\title{
I. Die Gründungsväter und die Entstehung der Großen Koalition
}

\section{Kiesingers Weg ins Kanzleramt}

Am Abend des 27. Oktober 1966 trafen sich in der Bonner Vertretung Baden-Württembergs an der Welckerstraße der Ministerpräsident, der Vorsitzende der CDU Nordwürttembergs, Klaus Scheufelen, die beiden stellvertretenden Vorsitzenden des Wirtschaftsrats der Partei, Alphons Horten und Josef Rust, der Landesminister Baden-Württembergs, Adalbert Seifriz, und der Geschäftsführer und stellvertretende Vorsitzende der CDU, Josef Hermann Dufhues. Alle waren aus ähnlichen Gründen in die Bundeshauptstadt gekommen, denn es fanden Sitzungen verschiedener Ausschüsse, des Wirtschaftsrats und anderer Parteigremien statt. Kiesinger reiste aus Stuttgart wegen einer am nächsten Tage anberaumten Bundesratssitzung an; Scheufelen hatte eine Verabredung mit dem bereits im September zurückgetretenen, aber noch immer amtierenden Staatsminister im Bundeskanzleramt, Ludger Westrick. Im Bundeskanzleramt wurde ihm allerdings mitgeteilt, Herr Westrick halte sich im Bundestag auf. So begab sich der CDU-Vorsitzende Nordwürttembergs ins Parlament, wo er die anderen im Foyer versammelt fand.

An diesem Donnerstag war die Regierung Erhard, die christlich-liberale Koalition, auseinandergebrochen. Erich Mende, der FDP-Vorsitzende und Vizekanzler, hatte gegen ein Uhr mittags den Bundeskanzler aufgesucht, um ihm den Rücktritt der vier FDP-Minister anzubieten. Der Kanzler nahm ihren Rücktritt an, die verwaisten Ressorts sollten aber zunächst durch amtierende CDU/CSU-Minister mitverwaltet werden. Erhard hoffte, daß die Liberalen wieder in das Kabinett zurückkehren würden. Aber von der Runde, die sich zufällig im Foyer des Bundestages versammelte, glaubte keiner mehr an eine Fortsetzung der Regierungskoalition - im Gegenteil. Auf Rust machte der Vorschlag, in die Vertretung Baden-Württembergs umzuziehen, den Eindruck einer „gezielten Abendunterhaltung “, um Kiesinger ins Gespräch für die Nachfolge Erhards zu bringen. Daß da eine "Schwabensache“ im Gange war, ahnte er schon aufgrund des Hinweises, man wolle in die Landesvertretung einkehren, angeblich „wegen des guten Weines“, den man dort vorrätig halte. Der frühere Staatssekretär erinnerte sich, daß Theodor Heuss ihm gegenüber einmal scherzhaft bemerkt hatte: „Den guten Wein trinken wir eh allein und nicht mit euch Preußen." Nun schenkten die Schwaben den Preußen ihren guten Wein ein. Da schien etwas dahinterzustecken ${ }^{1}$.

An diesem Abend wurde Kiesinger gefragt, ob er nicht glaube, daß Erhards Fähigkeiten als Politiker überschätzt worden seien. Erhard habe den Kontakt zur Partei und zu den politischen Strömungen in der öffentlichen Meinung verloren. Aber Kiesinger nahm den amtierenden Kanzler in Schutz: Eigentlich sei die Krise nicht durch Erhard verschuldet worden, sagte er. Nur die unbefriedigende Nachfolge von Staatssekretär Hans Globke im Bundeskanzleramt habe sie verursacht ${ }^{2}$. Kiesinger betonte, ein neuer Kanz-

' Rust, Gespräch mit dem Verfasser, 3.2.1988.

${ }^{2}$ Scheufelen (Gespräch mit dem Verfasser, 27.11.1987) erinnert sich zum Beispiel daran, daß Globke dafür sorgte, daß führende Parteipolitiker aus den Landesverbänden spätestens innerhalb von zwei Tagen einen Termin bei Adenauer bekamen, wenn sie darum baten. In der Regierung Erhard sei das nicht möglich gewesen. 
ler müsse unbedingt auf die Klärung dieser Frage - der Nachfolge Westricks im Kanzleramt - dringen und fügte scheinbar beiläufig hinzu: „Ich würde nicht Bundeskanzler werden wollen, wenn ich die Stelle nicht mit einem erstklassigen Fachmann besetzen könnte." "Wollen Sie denn eigentlich Bundeskanzler werden?" fragte jemand zurück ${ }^{3}$. Bis zu diesem Zeitpunkt war über die Kanzlernachfolge noch nicht geredet worden. Aber man spürte, daß es einzig und allein um diese Frage ging. Kiesinger zögerte nicht: „Ja, Sie aber, Herr Rust, waren Stellvertreter von Herrn Globke. Sie kennen den Laden. Wären Sie bereit, Staatssekretär zu werden?" An diesem Abend sagte Rust spontan zu. Später kam er aber darauf nicht mehr zurück. Für Kiesinger war dennoch der erste Schritt getan: Er hatte seine Bereitschaft erklärt, sich um das Kanzleramt als Kandidat der Union zu bewerben ${ }^{4}$.

\section{Auf dem Weg ins Palais Schaumburg - Unterstützung der CSU}

Seit seinem Weggang nach Stuttgart 1958 hatte Kiesinger darauf gehofft, eines Tages als Minister oder gar als Bundeskanzler nach Bonn zurückzukehren. Nach der Bundestagswahl 1961 sollte er auf Wunsch des württembergischen Landesverbandes der FDP zum Außenminister einer christlich-liberalen Regierung gemacht werden. Kiesinger sei informiert und habe zugesagt, hieß es damals. Falls die Union sich damit einverstanden erkläre, werde es für die Liberalen leichter sein, einen Kanzler Adenauer zu akzeptieren $^{5}$. Am Ende wurde Gerhard Schröder Außenminister, Kiesinger blieb in Stuttgart. Aber er rechnete auch weiterhin damit, daß eines Tages der Ruf an ihn ergehen werde. Um sich in Erinnerung zu bringen, schrieb er Anfang 1964, auf Anraten des Altbundespräsidenten Heuss, einen kurzen Abriß seiner Schwäbischen Kindheit, der im gleichen Jahr zusammen mit einigen Reden veröffentlicht wurde ${ }^{6}$.

Zwei Jahre später - Erhard hatte inzwischen Adenauer als Bundeskanzler abgelöst geriet die christlich-liberale Bundesregierung wegen einer Haushaltslücke von vier Milliarden DM in eine Krise, die zu ihrem Sturz führte. Die Koalitionspartner vermochten sich nicht zu einigen, ob der Haushalt durch Kürzungen im Sozialetat oder durch Steuererhöhungen ausgeglichen werden solle. Eine Reise Erhards Ende September 1966 nach Washington verschlechterte die Lage dramatisch, da der Kanzler den amerikanischen Präsidenten Johnson nicht von einem dringend benötigten Aufschub der Devisenausgleichszahlungen überzeugen konnte. Damit war das Ende der Regierung abzusehen. Kiesinger begann sich allerdings schon im Juli 1966, als die Union bei der Landtagswahl in Nordrhein-Westfalen eine schwere Niederlage erlitt', auf die Möglichkeit vorzube-

\footnotetext{
${ }^{3}$ Scheufelen, Gespräch mit dem Verfasser, 27.11.1987.

${ }^{4}$ Vgl. Gerstenmaier, Streit und Friede, S. 535; dort heißt es, Scheufelen habe die Kandidatur Kiesingers über den Landesverband Baden-Württemberg zur Debatte gestellt. Damit bestätigt Gerstenmaier indirekt, daß die Unterredung am Abend des 27.10.1966 Teil einer gezielten Aktion gewesen ist.

${ }^{5}$ Die FDP war mit der Aussage in die Wahl gegangen, in ein Kabinett unter der Führung von Erhard oder einem anderen Nachfolger Adenauers aus den Reihen der Union einzutreten. Siehe Baring, Sehr verehrter Herr Bundeskanzler, S. 355, zu dem Vorschlag, Kiesinger zum Außenminister zu berufen. Der baden-württembergische Justizminister Wolfgang Haußmann regte das am 11.10.1961 Krone gegenüber an. Am selben Tag erklärte Kiesinger auf einer Pressekonferenz, das Amt des Außenministers interessiere ihn; vgl. Süddeutsche Zeitung, 12.10.1961. Krone (Aufzeichnungen, zitiert nach Baring, S. 355) hielt in seinen Notizen über Kiesinger fest, der den Liberalen schon eine Zusage gegeben hatte: „Den läßt der Ehrgeiz auch nicht schlafen.“

${ }^{6} \mathrm{Vgl}$. Kiesinger, Ideen.

7 Die CDU verlor 3,6 \% und sank auf 42,8 \%, die SPD aber gewann 6,2 \% der Stimmen, stieg auf 49,5\% und blieb nur ein Mandat unter der absoluten Mehrheit.
} 
reiten, bei einer Kabinettsumbildung als Minister benannt zu werden oder gar als Kanzler selbst eine Regierung bilden zu müssen. Aus Bonn ließ er Akten zur Außenpolitik herbeischaffen, um sich über die Entwicklung im Verhältnis zu den wichtigsten Bündnispartnern und über den Stand der Ostpolitik zu informieren. Er nutzte zudem die letzte Phase der Regierungskrise im Oktober dazu, um sich nach der Stimmung bei den süddeutschen Landesverbänden der Union hinsichtlich seiner Kandidatur als Kanzler zu erkundigen. Am wichtigsten war dabei die Haltung der CSU. Ohne ihre Unterstützung hätte es der Schwabe nicht gewagt, zu kandidieren.

Die Schwesterpartei der CDU besaß bei der parteiinternen Auswahl das entscheidende Votum. Ihr Vorsitzender, Franz Josef Strauß, kam nach dem schmählichen, 1962 im Zuge der Spiegel-Affäre von der FDP veranlaßten Abgang als Verteidigungsminister für das Amt des Kanzlers noch nicht in Frage. Daher war vollkommen offen, für wen sich die CSU, die immerhin ein Fünftel der Unions-Abgeordneten stellte, am Ende entscheiden würde. Allen Kandidaten war von vornherein klar, daß das Münchner Votum den Ausgang bestimmte.

Über Scheufelen, den Vorsitzenden des CDU-Landesverbands Nordwürttemberg, ließ Kiesinger bei den Münchnern vorfühlen, wie der Verband die Chancen seiner Kanzlerkandidatur beurteile. Scheufelen wandte sich nicht an den Vorsitzenden Strauß, sondern sprach mit dem Generalsekretär der Partei, Anton Jaumann. Anfang November brachte der Münchner die Antwort ${ }^{8}$ : Die Christlich-Soziale Union werde hinter Kiesinger stehen, versicherte er.

Was sprach aus Münchner Sicht für den baden-württembergischen Ministerpräsidenten? Neben Kiesinger gab es noch drei weitere Bewerber um die Kandidatur: Schröder, den Fraktionsvorsitzenden Rainer Barzel und Bundestagspräsident Eugen Gerstenmaier. Weder der frühere Außenminister Schröder noch der Fraktionsführer Barzel besaßen aus unterschiedlichen Gründen allerdings - eine Chance. Mit dem Protestanten Schröder hatten die katholischen Bayern wenig im Sinn; gegen ihn sprach nicht nur, daß er der FDP nahestand, sondern auch seine offen demonstrierte Distanz gegenüber Paris und der Politik de Gaulles. Ein enges Zusammengehen zwischen Frankreich und der Bundesrepublik strebte dagegen der CSU-Vorsitzende an. Die Unterstützung der CSU für Barzel kam schon deswegen nicht in Frage, weil der 42jährige als Kanzler den neun Jahre älteren Strauß möglicherweise für immer von diesem Amt fernhalten konnte. Falls Barzel gewählt werde, so rechnete man in der CSU, könnte sich die nächste Gelegenheit für Strauß, ins Palais Schaumburg zu ziehen, vielleicht erst nach fünfzehn oder gar zwanzig Jahren ergeben - nach Barzels Amtszeit und einer Oppositionsperiode von CDU/CSU.

Anders sah es mit Kiesinger aus, der elf Jahre älter war als Strauß. Der Schwabe würde dem Bayern nicht auf lange Sicht im Wege sein. Diesen „Vorzug“ besaß auch Gerstenmaier. Tatsächlich war der Bundestagspräsident der ernsthafteste Konkurrent des Ministerpräsidenten. Aber gegen Gerstenmaier sprachen einige andere Faktoren. Zunächst: Er besaß kein Gespür für Opportunität. Nach der Wahlniederlage der Union in Nordrhein-Westfalen im Juli 1966 war Gerstenmaier mit der Erklärung vorgeprescht, er stehe als Kanzler zur Verfügung. Damals war die Partei zu einem Sturz Erhards noch nicht bereit. In seiner Jagdhütte im Vier-Herren-Wald überredeten ihn Dufhues, Bruno Heck

\footnotetext{
${ }^{8}$ Vgl. Knorr (Entscheidungsprozeß, S. 69), der behauptet, Kiesinger habe sich schon im August 1966 mit Jaumann getroffen und sich ihm in Erinnerung gebracht. Von Eschenburg (Gespräch mit dem Verfasser, 7.12.1987) kommt der Hinweis, daß sich im November 1966 Vertreter der CSU mit Kiesinger in Tübingen getroffen hätten.
} 
und Strauß gemeinsam dazu, diese „Kandidatur“ zurückzuziehen9. Hinzu kam beim Bundestagspräsidenten die Unsicherheit, ob er als Kanzler Wählerstimmen auf sich ziehen könne. Die Bayern brauchten einen populären Mann. Am 20. November 1966 standen die Landtagswahlen bevor, bei denen auch über die Entscheidung in Bonn mit abgestimmt werden würde! Kiesinger hatte seine Fähigkeiten als Wahlkämpfer mit seinem glänzenden Sieg von 1964 bewiesen, als er für die CDU in Baden-Württemberg das erste Mal die absolute Mehrheit gewann. Vor allem aus dieser Perspektive schien der Ministerpräsident der aussichtsreichste Kandidat zu sein. Schließlich wurzelte Kiesinger in einem süddeutschen Land und war nicht Teil der Bonner Politik. Als Landespolitiker würde er die Belange der Länder gegenüber Bonn besser verstehen und stärker unterstützen, als das von Gerstenmaier zu erwarten war ${ }^{10}$. In München war man außerdem daran interessiert, den eigenen, unbequemen Parteivorsitzenden zusätzlich mit einer anderen Aufgabe zu beschäftigen. Deshalb zeigte sich der CSU-Parteivorstand daran interessiert, daß der Kanzlerkandidat auf jeden Fall Strauß auf einen Kabinettsposten berief. Kiesinger hatte das zugesagt.

\section{Strauß verrechnet sich}

Strauß befand sich in der tröstlichen Situation, zwar nicht selbst Kanzler werden zu können, aber zu bestimmen, wer dafür in Frage kam. Von zweihundertfünfzig Stimmen gehörten 49, also gut ein Fünftel, der Unions-Fraktion, der CSU. Sie konnte zwar selbst keinen Kanzler küren, aber den Sieg jedes Kandidaten verhindern. Daher fühlten alle vier Kandidaten beim Vorsitzenden der CSU vor. Selbst einem Gespräch mit Schröder - es hatte nie zuvor eines stattgefunden - ging Strauß jetzt nicht mehr aus dem Weg, und er überraschte seine Parteifreunde nach diesem Treffen mit der Feststellung, in der Sache seien sie beide zwar weit auseinander, menschlich verstehe er sich aber mit Schröder ganz gut ${ }^{11}$. Ein ganz neuer Zug war im November 1966 an dem sonst so unberechenbaren und aggressiven CSU-Landesvorsitzenden zu erkennen. Wenn er durch die Gänge des Bundeshauses schlendere, Hände schüttelnd, Termine ausmachend, Erkundungen nach dem Wohlbefinden der Frau Gemahlin einholend, beobachtete der Journalist Hans Ulrich Kempski, dann müsse er jedem als Mann ohne Feinde vorkommen, als „ein rundherum netter Kerl“"

Strauß verstellte sich nicht. Er sah der Zukunft gelassen entgegen. Alles lief anscheinend in seine Richtung. Gesetzt hatte er auf den Bundestagspräsidenten. Er könne sich darauf verlassen, daß die CSU ihn unterstützen werde, versicherte er Gerstenmaier. Strauß erzählte das auch Kiesinger. Für ihn komme nur Gerstenmaier in Frage - aus Gründen des Konfessionsproporzes ${ }^{13}$. Er sei nicht gegen ihn, erklärte Strauß seinem baden-württembergischen Kollegen, er respektiere ihn, aber er sei lediglich sein zweiter Kandidat.

Das war für Kiesinger eine bittere Auskunft. Würde es Strauß am Ende doch gelingen, die CSU auf seinen Kandidaten einzuschwören? Kiesinger sicherte sich ab. Öffentlich erklärte er am 6. November, drei Tage vor der Nominierung, sein Ehrgeiz zwinge ihn

\footnotetext{
${ }^{9}$ Vgl. Heck, Gespräch mit dem Verfasser, 4.10.1988.

${ }^{10}$ Gerstenmaier (Streit und Friede, S. 538) klagte später, der starke Parteichef Max Huber [gemeint ist vermutlich der stellvertretende Parteivorsitzende und Landtagsfraktionsvorsitzende der CSU, Ludwig Huber] habe ihn als Zentralisten, nicht als Föderalisten eingeschätzt und daher seine Wahl nicht unterstützen wollen.

$11 \mathrm{Vgl}$. Christ und Welt, 4.11.1966.

${ }^{12}$ Süddeutsche Zeitung, 7.11.1966.

${ }^{13} \mathrm{Vgl}$. Knorr, Entscheidungsprozeß, S. 69.
} 
keineswegs dazu, nach Bonn zu gehen ${ }^{14}$. Für sich selbst dachte er daran, zumindest den Posten des Außenministers zu übernehmen, falls Gerstenmaier mit Unterstützung der CSU zum Kandidaten gewählt würde. Drei Tage vor der Abstimmung in der Fraktion suchte der Ministerpräsident den Bundestagspräsidenten auf. Auf den Kanzlerstuhl ziehe es ihn nicht, begann Kiesinger vorsichtig, ob er nicht bei ihm, Gerstenmaier, Außenminister werden könne?

Das war zwar nicht ganz glaubwürdig. Aber mit dem entwaffnenden Argument, dem alten Kollegen den Vortritt lassen zu wollen, hatte Kiesinger Erfolg. Sein schwäbischer Landsmann analysierte die Lage zunächst skeptisch: Eine neue Koalition mit der FDP käme offensichtlich nicht in Frage. Von der SPD und einem Teil der CDU könne er aber keine hinreichende Unterstützung erwarten, was er innenpolitisch für unbedingt notwendig halte. Zudem könnten die Folgen einer Großen Koalition für die CDU recht bedenklich werden ${ }^{15}$. Dennoch wolle er nicht immer nein sagen. Er, Gerstenmaier, wolle antreten, sofern er die ihm zugesagte Unterstützung der CSU tatsächlich erhalte. Ohne diese werde er nicht kandidieren. In diesem Fall werde Kiesinger Kanzler. Und er, Gerstenmaier, wäre bereit, Kiesingers Außenminister zu werden. Kiesinger sei sofort darauf eingegangen, schreibt Gerstenmaier im Rückblick. „Wir versprachen uns, wenn der eine von uns Bundeskanzler werde, solle der andere sein Außenminister werden. "16

Alles hing also von Strauß und seiner Partei ab. Gerstenmaier traute den Zusagen ihres Vorsitzenden. Es gab für ihn keinen Grund anzunehmen, daß die CSU ihm ihre Gefolgschaft verweigern würde. Aber es kam anders. Von den Überlegungen, die Jaumann und der Fraktionsvorsitzende im bayerischen Landtag, Ludwig Huber, im Hinblick auf Kiesinger inzwischen angestellt hatten, wußte Strauß offenbar nichts. Als er Scheufelen im Rahmen einer CDU-Wirtschaftsratssitzung Anfang November in Berlin traf, fragte er seinen Kollegen, wer denn die Nachfolge Erhards antreten werde. Auf die Antwort Scheufelens: „Na, der Kiesinger“, schüttelte Strauß seinen Kopf: „Ah geh, du immer mit deinem Kiesinger. "17 Es überraschte den Schwaben, daß der bayerische Parteivorsitzende allem Anschein nach nicht über die Vorgänge in seiner Partei informiert war. Er schlug Strauß vor, erst einmal selbst nach München zu fahren und sich über die Stimmung in seiner Partei zu informieren.

Ob er es getan hat? Noch zwei Tage vor der Entscheidung gab Strauß dem Journalisten Kempski vertraulich zu erkennen: Alles laufe nun auf Barzel oder Schröder als Kandidaten hinaus. Aber als am 9. November 1966 der CSU-Vorstand in München über seine Kandidaten-Empfehlung beriet, verwendete sich Strauß für keinen der vier, nicht einmal für Gerstenmaier. Zu Beginn der Sitzung machte er lediglich klar, daß Schröder für ihn als Kandidat nicht in Frage komme. Heck, der als Beobachter an der Sitzung teilnahm, erklärte später, daß es Strauß lediglich darauf angekommen sei, das Votum seiner Partei für sich selbst als Kanzlerkandidaten zu erhalten. Es handelte sich um ein reines Vertrauensvotum; denn als Kandidat stand Strauß nicht zur Verfügung. Als der Vorstand sich für ihn als Kanzler ausgesprochen hatte, habe er die Parteinahme für Kiesinger toleriert, ohne selbst zu sprechen ${ }^{18}$. In einer geheimen Abstimmung unterstützten

\footnotetext{
${ }_{14}$ Vgl. Frankfurter Allgemeine Zeitung, 7.11.1966.

15 Vgl. Gerstenmaier, Streit und Friede, S. 537. Damit meinte er vermutlich, daß die SPD durch eine Regierungsbeteiligung aufgewertet würde und die Union vielleicht allmählich in die Opposition gedrängt werden könnte.

16 Gerstenmaier, Streit und Friede, S. 537.

17 Scheufelen, Gespräch mit dem Verfasser, 27.11.1987.

${ }_{18} \mathrm{Vgl}$. Heck, Gespräch mit dem Verfasser, 4.10.1988.
} 
etwa 90 Prozent der sechzig Anwesenden die Bitte, Strauß möge sich zur Kanzlerkandidatur bereit erklären. Der Vorsitzende nahm das zur Kenntnis, lehnte aber ab. Dann fiel die Wahl auf Kiesinger. Gleichzeitig forderte die Partei einen Kabinettsposten für ihren Vorsitzenden. Ein Ministeramt lehnte Strauß natürlich nicht ab. Das war die Gegenleistung, die Kiesinger erbringen mußte.

Damit war die Bonner Wahl schon am Vortag entschieden. Gerstenmaier hörte die Nachricht über den Rundfunk in seinem Bundestagsbüro. Er wußte, daß er jetzt keine Chance mehr besaß, vielmehr Kiesinger der Mann der Stunde war. Sofort erklärte er in einem Brief an die Fraktion, daß er seine Kandidatur zurückziehe. Er habe sich zu einem Zeitpunkt bereit erklärt, am Auswahlwettbewerb teilzunehmen, als die Stellungnahme der CSU noch nicht zu übersehen gewesen sei. Außerdem sei er nicht bereit, gegen den Ministerpräsidenten seines eigenen Landes zu kandidieren ${ }^{19}$.

\section{Der gefährdete Kandidat: Die Vergangenbeit holt Kiesinger ein}

Das mögliche Votum der CSU für Gerstenmaier stellte nicht die einzige Unwägbarkeit für den baden-württembergischen Ministerpräsidenten auf dem Weg ins Palais Schaumburg dar. Kaum war sein Name in der Debatte um die Nachfolge von Kanzler Erhard gefallen, da kam aus der Schweiz die Mahnung, die nahe Vergangenheit nicht zu vergessen. Die Neue Zürcher Zeitung verwies darauf, daß kurz zuvor dem Bundesratsdirektor Albert Pfitzer, der als Nachfolger von Westrick im Bundeskanzleramt vorgesehen war, als ehemaligem SS-Mitglied der Staatssekretärsposten verweigert worden war, während jetzt ein Parteimitglied der NSDAP zum Bundeskanzler gewählt werden solle. Damit nicht genug. Kiesingers Kandidatur schien wirklich gefährdet zu sein, als ein Mitarbeiter der amerikanischen Botschaft in Bonn Gerüchte über eine angebliche SA- oder sogar SS-Mitgliedschaft nach Washington übermittelte. Die Washington Post verbreitete am 5. November 1966 die unzutreffende Behauptung, daß Kiesinger als SA-Offizier und Politischer Kommissar der Wehrmacht gedient hatte ${ }^{20}$.

Tatsächlich war Kiesinger von April 1940 bis zum Kriegsende als dienstverpflichteter Wissenschaftlicher Hilfsarbeiter im Auswärtigen Amt beschäftigt. Den Gestellungsbefehl in der Tasche und somit das düstere Schicksal als Frontsoldat vor Augen, hatte der Privatlehrer und Rechtsanwalt die vielleicht moralisch anfechtbare, aber menschlich verständliche Entscheidung getroffen, sich dem Kriegsdienst durch die Dienstverpflichtung zu entziehen. „Ich hatte mir geschworen, sie [Kiesingers Ehefrau Marie-Luise] und das erwartete Kind [Viola], was an mir lag, heil durch den Krieg zu bringen. Das Wort des Horaz, daß es süß und würdig sei, fürs Vaterland zu sterben, hatte schon im Ersten Weltkrieg seinen Sinn verloren. "21 In der Abteilung des Auslandrundfunks Kult R wurde er Verbindungsmann zum Propagandaministerium und stieg schließlich 1942 sogar zum stellvertretenden Abteilungsleiter auf. Diese Beförderung verdankte Kiesinger wesentlich seinem überzeugenden Auftreten und besonderen Verhandlungsgeschick, das ihn unter den anderen Mitarbeitern herausragen ließ - nicht so sehr seiner Parteizugehörig-

\footnotetext{
${ }^{19}$ Vgl. Die Welt, 10.11.1966, und Süddeutsche Zeitung, 11.11.1966; Gerstenmaier nannte es gegenüber Journalisten einen „unglaublichen Vorfall“, daß sich die CSU öffentlich vor der Wahl zu einem der Kandidaten bekannt hatte.

20 Vgl. Washington Post, 5.11.1966. Wörtlich heißt es dort: „A Nazi Party member from 1933 to May 8, 1945, served as a liaison officer between the Foreign Office and Josef Goebbels, Propaganda Ministry, and later as an SA officer and political commissar with the Wehrmacht."

21 Kiesinger, Jahre, S. 215.
} 
keit $^{22}$. Für Kiesinger war die Position im Amt in zweifacher Hinsicht wertvoll. Sie schützte ihn nicht nur vor dem Kriegsdienst, sondern erlaubte es ihm, seine Distanz zum herrschenden Regime zu bewahren. Denn eine Hochburg der NSDAP war das AA nicht. Günter Diehl, selbst Mitglied im AA, erläutert, die Leute im Auswärtigen Dienst hätten aus oft jahrelanger persönlicher Erfahrung im Ausland ein zutreffendes Bild von den Interessen anderer Völker gewonnen. Dies habe zwangsläufig zu einer kritischen Bewertung des Nationalsozialismus als politischer Bewegung wie seiner Führer geführt ${ }^{23}$. Auch der Historiker Hans-Jürgen Döscher bestätigt dieses Bild. Sein Buch handelt von dem schließlich gescheiterten Versuch der Nationalsozialisten, das Auswärtige Amt durch Besetzung der Schlüsselpositionen grundlegend zu reformieren. Er gelangt zu dem Schluß, die Abhängigkeit von der „traditionellen“ Berufsdiplomatie wie das „Anpassungs- und Beharrungsvermögen der meisten Berufsdiplomaten gegenüber dem NS-Regime" hätten radikale Reformen der Nationalsozialisten im Auswärtigen Dienst verhindert ${ }^{24}$.

Man hat sich schwer getan, die Tätigkeit Kiesingers im Auswärtigen Amt nachträglich zu bewerten. Sie wurde auch unter denen als Makel, als trüber Punkt auf einer sonst glanzvollen Karriere empfunden, die Kiesinger gegenüber freundlich gesonnen blieben ${ }^{25}$. Diehl, ein Vertrauter Kiesingers, meint abschließend, als stellvertretender Abteilungsleiter habe Kiesinger eine "wichtige Funktion “ ausgeübt ${ }^{26}$. Es sei vielleicht der große Irrtum Kiesingers gewesen, schreibt Martin Hirsch, der ehemalige Richter am Bundesverfassungsgericht und Schüler des Privatlehrers, daß dieser gehofft habe, „das Naziregime könne doch erträglicher werden oder gar sich selbst kurieren"27.

Kiesinger selbst sah das freilich anders. Was ihn an der plötzlich im November 1966 aufkommenden Debatte am stärksten erbitterte, war die Tatsache, daß die Anschuldigungen aus dem Ausland und aus der DDR nicht nur in den bundesdeutschen Zeitungen weitergegeben, sondern von der Öffentlichkeit in ihrem Wahrheitsgehalt nicht angezweifelt wurden. Er litt darunter, daß man seinem Wort nicht mehr Glauben schenkte. „Die Redlichkeit wird einem bestritten“, klagte er später. „Das ist das Schlimmste. Die Redlichkeit wird bestritten. “" 28

${ }^{22}$ Vgl. Diehl, Kiesinger, S. 180.

${ }^{23}$ Vgl. ebenda sowie Thielenhaus, Anpassung und Widerstand, S. 24 ff.; über die Ziele und das Schicksal des Kreises junger Diplomaten um Staatssekretär Ernst von Weizsäcker siehe Thielenhaus und Blasius, Großdeutschland.

${ }^{24}$ Döscher, Auswärtiges Amt, S. 309. Ob dies auch für die Abteilung Kult R zutrifft, zieht zumindest Peter Longerich (Propagandisten) in Zweifel. Zwar liegt für Longerich die Leistung des Referats von Kiesinger wesentlich im organisatorischen Bereich, im Aufbau eigener Rundfunkeinrichtungen im Ausland, die sich der Kontrolle des Propagandaministeriums entziehen sollten (S. 49). Über die Inhalte der Propagandaarbeit des Amtes stellt er allerdings insgesamt fest (S. 330): „Trotz gewisser Unterschiede in Methode und Schwerpunktsetzung war die Propaganda des AA doch durch eine große inhaltliche Übereinstimmung mit der vom Propagandaministerium verfolgten Linie gekennzeichnet und nicht durch einen durchgehend eingehaltenen alternativen Kurs. [...] War es generell ein Hauptanliegen nationalsozialistischer Selbstdarstellung, nach außen hin den Anschein größtmöglicher Geschlossenheit zu erwecken, so waren auch die Bemühungen in der Kriegspropaganda vordringlich darauf gerichtet, das Nebeneinander unterschiedlicher Positionen zu vermeiden. Die Vorstellung, mit differierenden Propagandaaussagen vor das Publikum zu treten, gehörte zu den größten Ängsten der NS-Propagandisten.“

${ }^{25}$ Vgl. etwa Henkels, Der dritte Bundeskanzler, Frankfurter Allgemeine Zeitung, 2.12.1966; Hans Werner Kettenbach, Mit Verspätung auf den Schild gehoben, Kölner Stadtanzeiger, 1.12.1966. Würdigungen aus Anlaß des Todes von Kiesinger enthielten kaum noch eine Wertung seiner Tätigkeit im AA, mit einer Ausnahme: Der Bundeskanzler der Großen Koalition, Der Tagesspiegel, 10.3.1988.

${ }^{26}$ Diehl, Kiesinger, S. 180.

${ }^{27}$ Oberndörfer (Hrsg.), Begegnungen, S. 100.

${ }^{28}$ Hermann Schreiber, Keine Rede von Kraft und Herrlichkeit, in: Geo Special Bonn 6 (1985), S. 45. 
Das Mißtrauen ihm gegenüber schien dem langjährigen Abgeordneten und Ministerpräsidenten nicht nur wegen seiner Verdienste als hervorragender Politiker in der Aufbauphase der Bundesrepublik ungerechtfertigt zu sein. Kiesinger nahm für sich auch in Anspruch, nie Nationalsozialist gewesen zu sein. Er sei zwar im Mai 1933 der Partei beigetreten. Aber Freunde und Bundesbrüder seiner und anderer katholischer Verbindungen hätten das auch getan. Gab es nicht Chancen, verteidigte sich Kiesinger später, die Richtung dieser neuen Bewegung mitzubestimmen? Das habe man damals naiv gehofft ${ }^{29}$.

Aber dann 1934, nach dem „Röhm-Putsch“, als Hitler den Mord an Mitgliedern der SA und einigen anderen, wichtigen Persönlichkeiten der Weimarer Zeit nachträglich legalisierte und damit die Rechtsstaatlichkeit aufhob - da habe er sich innerlich vom $\mathrm{Na}$ tionalsozialismus abgewandt. Nicht nur habe er die Partei nicht mehr unterstützt, sondern - wo es ging - auch ihre Autorität untergraben. „Wenn ich auch nur ein sogenannter Mitläufer gewesen wäre, wenn ich nicht wirklich Widerstand geleistet hätte und Kopf und Kragen riskiert hätte, hätte ich mich nicht um die Kanzlerwürde beworben“, machte der Kanzler gegenüber Alfred Wolfmann, dem Korrespondenten einer israelischen Zeitung, im Dezember 1966 deutlich $^{30}$. Er habe von 1934 an ständig gegen die nationalsozialistische Bewegung gelebt, sich in die „innere Emigration“ zurückgezogen ${ }^{31}$.

Zweimal hat er sich in der Zeit von 1934 bis 1939, in der er als Repetitor privat Jurastudenten unterrichtete, tatsächlich erfolgreich für bereits Inhaftierte bei der Gestapo eingesetzt. Um den Schüler Ernst Wolf aus der Gewalt der politischen Polizei des NSRegimes zu befreien, sprach Kiesinger dreimal im Reichssicherheitshauptamt vor. Man hatte Briefe des jungen Studenten abgefangen, in denen dieser das nationalsozialistische Regime anklagte. Es gelang Kiesinger schließlich, Wolf freizubekommen. Auch einen Prokuristen, dem man Devisenvergehen zur Last legte, konnte Kiesinger vor einer Verlängerung der Haft retten. Trotz strenger Devisenbewirtschaftung hatten einige katholische Ordensgemeinschaften größere Reichsmarkbestände nach Holland zu transferieren versucht. Da die Verantwortlichen geflohen waren, machte man den Prokuristen haftbar und stellte ihn vor Gericht. Die Nationalsozialisten nutzten den Prozeß zu einem Generalangriff gegen die katholischen Mönchsorden. Es gelang aber dem Anwalt Kiesinger, die schon verbüßte Zeit des Angeklagten in der Untersuchungshaft bei der Urteilsverkündung anrechnen zu lassen. Der Prokurist kam daher sofort auf freien Fuß.

Trotz seines Engagements in diesen beiden Fällen und trotz seiner grundsätzlich skeptischen Haltung gegenüber dem Nationalsozialismus, die ihm von vielen seiner Schüler aus jener Zeit bestätigt worden ist, erkannte Kiesinger, daß er sich nicht von der Schuld freisprechen konnte, die das deutsche Volk durch die NS-Verbrechen auf sich geladen hatte. „Das ist schlimm, daß wir - meine Generation - diese Zeit haben mitmachen müssen“, sagte er 1979 in einem Interview. „Auch wenn man noch so sehr anerkennt, daß

${ }^{29} \mathrm{Vgl}$. AdKASt, Kiesinger I - 226, D/1.2., A 008, Gespräch mit Wolfmann, 8.12.1966, und Hoff, Kiesinger, S. 57 f. In der "Askania“, der katholischen Verbindung Kiesingers in Berlin, drängten eine Reihe von führenden Vertretern verschiedener katholischer Vereine und Organisationen darauf, die NSDAP zu unterwandern, auf sie einen mäßigenden Einfluß auszuüben. Auf dieses Argument berief sich, laut Hoff, beispielsweise der Reichstagsabgeordnete der Deutschen Volkspartei, Martin Spahn, der für den Eintritt vieler Brüder der Verbindung „Burgundia“, einer benachbarten Organisation der Askania, verantwortlich gewesen sein soll.

${ }^{30} \mathrm{Vgl}$. Weg und Ziel, 1.2.1967.

${ }^{31}$ Vgl. BDC, Kiesinger, Mitglieds-Nr. 2633930, Eintritt: 1.5.1933. Die NSDAP-Mitgliedskarte Kiesingers zeigt, daß er offenbar nur bis zum November 1936 Mitgliedsbeiträge bezahlte. Oberndörfer (Begegnungen, S. 83 ff.) hat als Herausgeber einige der Schüler Kiesingers, wie etwa Jürgen Arndt, Wolf und Hirsch, zu diesem Thema zu Wort kommen lassen; siehe auch Diehl, Kiesinger, S. 175 f. 
das Zwänge waren, gegen die der einzelne tatsächlich nichts unternehmen konnte, man war eben ein Teil dieses Volkes, das sich geschichtlich in eine Situation hineinmanövriert hat, die schrecklich ist. Schrecklich nicht, daß sie den Krieg verloren hat, sondern schrecklich das, was eben in seinem Namen begangen worden ist. Deswegen kann ich mir nicht auf die Schulter klopfen. Das ist für mich das große Handikap gewesen." ${ }^{2}$

Kiesinger sah sich als Repräsentant der Mehrzahl der Deutschen, die unverschuldet in die Zeit des Nationalsozialismus hineingeraten und trotzdem im Land geblieben waren. Es waren die Mitläufer, die das Regime durch Mitgliedschaft in der Partei oder einfach nur durch ihre Gleichgültigkeit stützen halfen, die aber weder die Vernichtung der Juden wollten noch etwas mit ihr zu tun hatten. Dieser größte Teil der Deutschen sollte durch seine Kanzlerkandidatur mit dem neuen Staat versöhnt werden. Nicht ohne Selbstgerechtigkeit behauptete er damals: „Ein Mann mußte das einmal tun für alle die Deutschen, die in ähnlicher Lage sind, damit um so schärfer die Grenze gezogen wird zu den Verbrechern. “" ${ }^{33}$ Hervorragende deutsche und jüdische Repräsentanten teilten diese Sicht und ermutigten Kiesinger, sich um das Amt zu bewerben. Bundespräsident Heuss schrieb bereits 1964 in seinem Tagebuch, daß Kiesinger als Nachfolger Erhards sein Kanzlerkandidat sei. Der jüdische Verleger Karl Marx und der Berliner Propst und Widerstandskämpfer Heinrich Grüber, ein Überlebender des Vernichtungslagers Auschwitz, hatten Kiesinger im Herbst 1966 in der Schwarzwälder Villa von Marx zugeredet, daß gerade er als ehemaliges Mitglied der NSDAP im Sinne einer Aussöhnung mit der jüngsten Vergangenheit die politische Führung des Landes übernehmen müsse ${ }^{34}$.

\section{Das Weiße Haus ist mit einer Kandidatur Kiesingers einverstanden}

Aber Kiesinger war nicht der Mann, an dem die Polemik einfach abprallte. „Ich stehe das nicht durch", soll er einmal während der Wochen im Herbst gesagt haben ${ }^{35}$. Grüber erklärte er die Ohnmacht seiner Lage damit, daß er sich gegen die Vorwürfe nicht wehren könne: Wer sich zu rechtfertigen suche, der klage sich $a^{36}$. Ob Kiesinger eine gegen ihn gerichtete Kampagne wegen seiner NS-Vergangenheit aushalten würde, schien auch Kempski, einem Journalisten und hervorragenden Kenner der Bonner Szene, fraglich. Würde Kiesinger sich überhaupt in einen Kampf mit unsicherem Ausgang einlassen? „Wer ihn gut kennt, ist geneigt, beide Fragen spontan zu verneinen“, meinte er ${ }^{37}$.

Aber mittlerweile war sich Kiesinger seines Erfolges sicher. Diese persönliche Überzeugung stellte den Grund dar, zu bleiben und weiter auszuharren. Nach der öffentlichen Debatte über seine politische Vergangenheit mußte er nun klären, ob die amerikanische Regierung Vorbehalte gegen seine Kanzlerkandidatur hege und ob sie ihn akzeptieren würde. Scheufelen begab sich zum amerikanischen Botschafter in Bonn, George C. McGhee, und erklärte ihm, man würde gerne erfahren, wie Präsident Johnson zur Kandidatur Kiesingers stehe. McGhee sagte zu, sich mit Washington in Verbindung zu setzen. Scheufelen solle am nächsten Tag zum Mittagessen wiederkommen. Noch bevor der CDU-Vorstand am Nachmittag des 8 . November zusammentrat, um die Kandidatenliste zu beschließen, wurde der Vertrauensmann Kiesingers von McGhee über

\footnotetext{
${ }^{32}$ AdKASt, Kiesinger I - 226, F/, A 404, Gespräch mit Majer und Degen, 24.11.1979, S. 38.

${ }^{33}$ Weg und Ziel, 1.2.1967.

${ }^{34}$ Vgl. AdKASt, Kiesinger I - 226, F/3., A 322, Gespräch mit Löwe, 31.1.1978, S. 27.

${ }^{35}$ Der Spiegel, 14.11.1966, S. 37.

${ }^{36}$ Vgl. AdKASt, Kiesinger I - 226, F/3., A 322, Gespräch mit Löwe, 31.1.1978, S. 27.

${ }^{37}$ Süddeutsche Zeitung, 7.11.1966.
} 
die amerikanische Haltung informiert. Der Botschafter empfing seinen Gast mit einer Entschuldigung für das Durchsickern kritischer Informationen aus seinem Haus und richtete dann lediglich einen einzigen Satz aus: „Präsident Johnson lasse Kiesinger grüßen. “38

\section{Überraschende Wendung: Entlastung durch das Denunziationspapier}

Völlig unerwartet kam Hilfe auch von anderer Seite. Aus dem Archiv des Nachrichtenmagazins Der Spiegel erhielt Kiesinger am Tag vor der entscheidenden Wahl in der Unionsfraktion ein Dokument, daß ihn politisch entlastete. Das Papier war im Rahmen von Recherchen für Heinz Höhnes SS-Buch Der Orden unter dem Totenkopf in den Washingtoner National Archives ausgegraben worden. Der stellvertretende Chefredakteur des Hamburger Blattes, Conrad Ahlers, beschloß, das Dokument Kiesinger zuzuschicken. Ahlers konnte persönliche Gründe für diese Entscheidung anführen. Während der Spiegel-Affäre im Herbst 1962 hatte sich der baden-württembergische Ministerpräsident für den damals Angeklagten öffentlich eingesetzt. Der stellvertretende Chefredakteur war damals als Autor eines Artikels, der angeblich geheimes Material aus dem Verteidigungsministerium enthielt, auf Verlangen von Verteidigungsminister Strauß in seinem spanischen Ferienort Torremolinos verhaftet und von den spanischen Behörden nach Deutschland ausgeliefert worden. Einen Tag danach, am 9. Oktober 1962, nahm Kiesinger in einer Pressekonferenz den Journalisten in Schutz. Er wisse nicht, was im einzelnen gegen Ahlers vorliege, für einen Landesverräter halte er ihn aber nicht. Dankbar nahm Ahlers diese Worte zur Kenntnis. Aus der Haft in der Nähe von Bonn schrieb er an Kiesinger und schloß mit der Bemerkung: „Schade, daß Sie Ihre Praxis nicht mehr ausüben. Ich hätte Sie gerne als Verteidiger gewonnen. " ${ }^{39}$

Jetzt, fast genau auf den Tag vier Jahre später, war es Ahlers, der nicht nur zur Verteidigung Kiesingers beitrug, sondern mit der Übersendung des Dokumentes auch die Nominierung durch die Fraktion sicherstellte. Kiesinger nutzte die unerwartete Gunst der Stunde sofort. Über das Staatsministerium Baden-Württemberg ließ er das Dokument an die Fraktionsmitglieder verteilen. Aus einem vorangestellten, erläuternden Blatt ging hervor, daß dem Ministerpräsidenten die Abschrift eines am 7. November 1944 aufgenommenen Protokolls des Reichssicherheitshauptamtes zur Verfügung gestellt worden sei. Es betreffe seine Tätigkeit während des Krieges ${ }^{40}$. Nicht erwähnt wurde in der Abschrift der Name des Verfassers, Ernst Otto Dörries, eines Wissenschaftlichen Hilfsarbeiters (WHA) der Rundfunkpolitischen Abteilung im Auswärtigen Amt.

Worum ging es? Am 7. November 1944 verfaßte Dörries eine Denkschrift über die angebliche Sabotage antijüdischer Aktivitäten in der deutschen Auslandsinformation ${ }^{41}$. Er „enthüllte" in dem Papier eine Verschwörung in verschiedenen Organisationen wie

${ }^{38}$ Scheufelen, Gespräch mit dem Verfasser, 27.11.1987. Der Botschafter machte den für das Gerücht verantwortlichen Mann ausfindig, der daraufhin seinen Posten verlassen mußte.

${ }^{39}$ Oberndörfer (Hrsg.), Begegnungen, Ahlers an Kiesinger vom 10.11.1962, S. 286.

${ }^{40}$ Vgl. AdKASt, Kiesinger I - 226, D/V.2, A 303, Anlage zum Schreiben des Staatsministeriums Baden-Württemberg vom 9.11.1966.

${ }^{41}$ Vgl. Ahrens, Gespräch mit dem Verfasser, 9.8.1988. Noch heute ist unklar, welchem Zweck die Denunziation diente. Ahrens vermutet, daß es sich bei dem Schriftstück um eine Art Memorandum handelt. Der fanatische Dörries habe damit eine fixe Propagandaidee durchsetzen wollen. Das Dokument muß auch im Zusammenhang mit der Reichspolitik im Osten und dem Kampf zwischen den Konzeptionen Alfred Rosenbergs und Himmlers gesehen werden. Das Auswärtige Amt suchte nach einer eigenständigen Konzeption und nach Argumenten gegen die Politik des Reichsministers für die besetzten Ostgebiete. Vier Tage vor der Niederschrift, am 3. November 1944, hatte in einem 
dem Propagandaministerium, der Reichsrundfunkgesellschaft, der Rundfunkpolitischen Abteilung und anderen Abteilungen des Auswärtigen Amtes. Besonders Kiesinger stand im Blickpunkt der Kritik. Dörries behauptete: „In der rundfunkpolitischen Abteilung des Auswärtigen Amtes, der ich angehöre, ist es der frühere Verbindungsmann der Abteilung zum Pro[paganda]mi[nisterium] und zur Reichsrundfunkgesellschaft und jetzige stellvertretende Abteilungsleiter Kiesinger, der nachweislich die anti-jüdische Aktion hemmt. "42

Kiesinger, so gab Dörries an, habe die Durchführung einer Störmeldungsaktion um die Person Henry Fords verhindert, die zum Ziel hatte, die „antijüdische Debatte“ zu beleben. Ferner habe er eine Aktion („Offener Brief der europäischen Jugend an Roosevelt mit dem Angebot der Übernahme der europäischen Juden“) sowie die Einrichtung eines Geheimsenders „zur Förderung des Antijudaismus in den USA“ vereitelt. Darüber hinaus listete Dörries einige pessimistische Bemerkungen seines Vorgesetzten auf, so etwa Kiesingers Reaktion auf die von Dörries geäußerte Zuversicht in das Durchhaltevermögen des deutschen Volkes: „Da schätzen Sie aber die Leidensfähigkeit des deutschen Volkes sehr hoch ein. "Um den Defätismus Kiesingers zu unterstreichen, erwähnte der Verfasser, daß Kiesinger offensichtlich auf eine Verständigung mit den Engländern gehofft hatte. Diese Möglichkeit bestehe aber jetzt nicht mehr - so deutete der Autor zumindest die von Kiesinger an ihn gerichtete „befremdende Suggestivfrage“: „Sie wissen doch sicher, daß die Leute vom 20. Juli auch mit England Kontakt aufzunehmen versucht haben, aber abgeblitzt sind?" ${ }^{43}$

Warum wurde Kiesinger nicht sofort nach der Eingabe der Denunziation durch die SS verhaftet? Solche ungeschützt gesprochenen Äußerungen konnten gerade in der Zeit nach dem mißglückten Attentat vom 20. Juli leicht zur Verurteilung führen. Aber es geschah nichts. Kiesinger erhielt von der Existenz des Dokuments erst im November 1966 Kenntnis. Die Niederschrift mußte während der Fliegerangriffe auf Berlin verbrannt oder verschollen sein, so zumindest seine Erklärung ${ }^{44}$.

Ob es sich wirklich so zugetragen hat, muß auch dann offenbleiben, wenn ein anderes Dokument herangezogen wird, das sich auf der Mikrofilmrolle direkt hinter dem Dörries-Papier befindet ${ }^{45}$. Es handelt sich um einen Brief des SS-Verbindungsmannes Friedrich Klumm an den persönlichen Referenten Heinrich Himmlers, Rudolf Brandt.

Berliner Café ein Gespräch stattgefunden. Dort hatten sich Dörries und der SS-Obersturmbannführer Friedrich Klumm mit einem Verbindungsmann zum Leiter des SS-Hauptamtes Gottlob Berger getroffen. Zudem nahm an dem Gespräch Graf Fürstenberg aus Riga teil, der im Papier von Dörries erwähnt wird, und schließlich kam ein Referent aus der Rundfunkpolitischen Abteilung des Auswärtigen Amtes, Ahrens, hinzu. Thema der Unterhaltung war Andrej Wlassow - jener sowjetische General, der 1942 in Kriegsgefangenschaft geraten war und eine russische Nationalarmee gegen Stalin aufstellen wollte. Wlassow sollte Teil einer neuen deutschen Politik im Osten werden. Im Oktober 1944 war das Wlassow-Komitee als Vertretung eines nationalen Rußlands anerkannt worden, was vor allem auf Himmlers Betreiben zurückzuführen war. Vgl. Hillgruber, Weltkrieg, S. 116 f., sowie zu Bergers differenzierter ostpolitischen Konzeption Höhne, Der Orden, S. 384 ff. Dörries versucht in seinem „Memorandum“ eine Verbindung herzustellen zwischen denjenigen, die seine Propagandaidee angeblich torpedierten, und den Zielen, die Himmler mit Wlassow verfolgte.

${ }^{42}$ AdKASt, Kiesinger I-226, D/V.2, Staatsministerium von Baden-Württemberg vom 9.11.1966, S. 2.

${ }^{43}$ Ebenda, S. 4.

${ }^{44} \mathrm{Vgl}$. Kiesinger, Jahre, S. 254. In seinen Memoiren hat Kiesinger keine weitere Erklärung gefunden. Dort heißt es lediglich: „Fest steht, daß die Niederschrift von Dörries vom ,Chef des SSHauptamtes' an den ,Persönlichen Stab des Reichsführers SS' Himmler weitergeleitet worden ist." Siehe dazu auch Oberndörfer (Hrsg.), Begegnungen, S. 125.

${ }^{45}$ Vgl. NA, Washington, Akten des Reichsführers-SS, Rolle T 175/125, Chef des SS-Hauptamtes an den Persönlichen Stab Reichsführer-SS vom 20.11.1944. 
Klumm schickt darin das Dörries-Papier im „Nachgang“ zu einem Schreiben Gottlob Bergers an Himmler, in dem Berger das Nachreichen der Niederschrift angekündigt hatte. Tatsächlich entsteht hier der Eindruck, daß das Papier direkt in die Hände der SS fiel. Doch hat Himmler, der sonst alle wichtigen, auf dem Mikrofilm abgelichteten Dokumente mit seiner Paraphe zeichnete, das Papier von Dörries gar nicht gelesen. Das Original ist nicht von ihm abgezeichnet, und man muß davon ausgehen, daß die Archivaufnahme das Original zeigt, was Dörries übrigens nach dem Krieg selbst bestätigt hat ${ }^{46}$. Hinzu kommt, daß das Büro Rudolf Brandts mit dem Dokument nichts anzufangen wußte - das Papier löste offenbar bei Brandt keinerlei Gedanken an eine „Sicherheitsgefährdung" durch die genannten Personen aus. Die Denunziationsschrift wurde nicht weiter an die Gestapo, an den Chef des Sicherheitsdienstes, Walter Schellenberg, geleitet. Es verblieb vielmehr in der Stabsabteilung. Dort wußte man nicht so recht, wie mit dem Schriftstück umzugehen sei. Die Ablage der Dörries-Schrift bereitete den Sachbearbeitern Kopfzerbrechen. Man ließ sich den Brief von Berger an Himmler vom 4. November 1944 kommen und stellte fest, daß „diese beiden Schreiben nicht zusammengehören “47. Der Archivleiter Berg muß wohl noch einmal bei Klumm nachgefragt haben, bevor er handschriftlich paraphierte: „Abl., Berg 23/1.“ Danach ist das Dokument nicht mehr hervorgeholt worden.

\section{Der persönliche Hintergrund der Denunziation}

Wie immer der tatsächliche Vorgang ausgesehen haben mag, Kiesinger fühlte sich verraten, als er im November 1966 von dem Dokument erfuhr. Er habe damals den Referenten Dörries unvorsichtigerweise ins Vertrauen gezogen, schreibt er in seinen Memoiren ${ }^{18}$. Und in einem Fernsehgespräch erklärte Kiesinger, er habe sich in diesem Mitarbeiter getäuscht. Dörries hatte zum engeren Kreis des stellvertretenden Leiters der Rundfunkpolitischen Abteilung gezählt. Eine kleine Gruppe von Mitarbeitern traf sich regelmäßig zu einer Kaffeerunde. In diesem Zirkel sei beschlossen worden, wen man in die Abteilung aufnehmen solle und wen nicht, meint Hanns Dietrich Ahrens ${ }^{49}$. Diese Runde sei von Dörries beherrscht worden. Er besaß ein rhetorisches Talent, wußte seine Zuhörer zu faszinieren. Dörries sprach von Visionen eines in der Welt dominierenden Deutschen Reiches. Er glaubte an die Bestimmung des germanischen Volkes zu herrschen und an die Verderbnis und Bedrohung, die vom jüdischen Volk ausgehe. Er ließ sich durch mystische Literatur inspirieren, etwa durch die Bücher von Mathilde Ludendorff wie Die Judenmacht - ibr Wesen und Ende ${ }^{50}$. Es war eine eigene, abgeschottete Welt,

\footnotetext{
${ }^{46}$ Vgl. Ahrens, Gespräch mit dem Verfasser, 9.8.1988; dort auch das folgende Zitat. Im Jahre 1967 erklärte Dörries Ahrens in Leichlingen, es habe lediglich eine Kopie für seinen Privatbesitz gegeben.

${ }^{47}$ NA, Washington, Akten des Reichsführers-SS, Rolle T 175/125, Aktenvermerk vom 19.1.1945. ${ }^{48}$ Vgl. Kiesinger, Jahre, S. 252.

${ }^{49}$ Vgl. Ahrens, Gespräch mit dem Verfasser, 9.8.1988. Mitglieder waren der für England und das Empire zuständige Professor Reinhard Haferkorn und der Orientexperte Kurt Munzel. Ahrens gehörte nicht dazu. Kiesinger (Jahre, S. 252) schreibt, er habe Dörries vertraut, weil dieser ihn gebeten habe, den Schriftsteller Otto Rombach vor dem Propagandaministerium zu retten. Rombach weigerte sich, einen Propagandaroman zu verfassen. Er wurde in die Abteilung aufgenommen, wo man ihn in Ruhe ließ.

${ }^{50}$ Es war die Witwe „unseres Feldherrn“ Erich Ludendorff, wie sie in ihren Büchern schrieb. Beide gründeten 1926 den streng antisemitischen, antimarxistischen, antiklerikalen Tannenberg-Bund, der sich nach dem Verbot 1933 die „Deutsche Gotterkenntnis“ nannte.
} 
in der Dörries lebte, und man muß wohl auch hier nach Motiven für die Denunziation suchen.

Als das Auswärtige Amt Ende 1944 aus Berlin Richtung Westen verlagert werden sollte, um nicht länger den ständigen Bombenangriffen ausgesetzt zu sein, entschloß sich der Mitarbeiterkreis um Kiesinger, mit dem Amt umzuziehen. Nur einer wollte nicht mittun, sondern meldete sich an die Front. Dörries verstand die Argumentation Kiesingers nicht: Er wolle für eine verloren geglaubte Sache nicht sein Leben riskieren. Dieses Bekenntnis hat Dörries Kiesinger nicht verziehen. Die Bewunderung Dörries für den belesenen und redegewandten Juristen schlug in Verachtung um. Kurz darauf fertigte er die Niederschrift an, die Ahrens unterschrieb, angeblich ohne das Papier gelesen zu haben $^{51}$. Kiesinger selbst hat dagegen in dem Schriftstück ein Instrument gesehen, das im Kampf um die Propagandakonzeption eingesetzt worden sei. In seinen Memoiren wertet er es als eine Reaktion auf seinen Versuch, den Plan des Außenministers für einen antijüdisch ausgerichteten Sender in den USA abzuwehren ${ }^{52}$.

Da der ehemalige stellvertretende Abteilungsleiter im AA bis zu seiner Kanzlerkandidatur nichts von der Denunziationsschrift ahnte, hielt er auch nach dem Krieg lockeren Kontakt zu dem Verfasser. Zuletzt traf man sich zu einer gemeinsamen Wanderung auf der Schwäbischen Alb Anfang der sechziger Jahre. Ob er Kanzler werden solle, fragte der ehrgeizige Ministerpräsident seinen früheren Mitarbeiter. Dörries riet $\mathbf{z u}^{53}$.

\section{Zwang zur schnellen Koalitionsbildung: Barzels Kampfansage}

Am 10. November 1966 wurde Kiesinger nach drei Durchgängen zum Kandidaten von CDU/CSU gewählt. Aber Kiesinger konnte sich auf seinem Erfolg nicht ausruhen. Der Sieg über seine Konkurrenten würde erst mit einer Regierungsbildung besiegelt werden, und wie sich dabei Barzel und Schröder verhalten würden, war nicht vorherzusehen. Ihre Reaktionen ließen für den frisch gekürten Kandidaten nichts Gutes erwarten. Das galt insbesondere für den Fraktionsführer. Barzel war durch seine eigene Fraktion gedemütigt worden. Vierzehn Stimmen bedeuteten ein katastrophales Ergebnis. Alle Hoffnungen, die sich auf Versprechungen an Abgeordnete vor der Wahl stützten, waren vergebens geblieben. Auch der Brief Adenauers, den die nordrhein-westfälischen Freunde Barzels unter der Hand zirkulieren ließen, verfehlte offenbar seine Wirkung. In ihm hatte der Altbundeskanzler den Fraktionschef aufgefordert, als Kanzler erneut eine christlich-li-

${ }^{51}$ Vgl. Ahrens, Gespräch mit dem Verfasser, 9.8.1988. Kiesinger soll im kleinen Kreis auf Ahrens geschimpft haben: Ahrens müsse endlich mal diesen Colin Ross abwimmeln. Ross, ein damals bekannter Schriftsteller, hatte 1936 sein wichtigstes Buch „Unser Amerika“ (Leipzig) publiziert, in dem er den deutschen Einfluß in den USA in euphorischer Weise darstellte. 1942 veröffentlichte er "Die Westliche Hemisphäre als Programm und Phantom des amerikanischen Imperialismus" (Leipzig), eine polemische Abrechnung mit der Politik Roosevelts, die in der These gipfelt, der Kriegseintritt der USA sei Teil einer jüdischen Weltverschwörung gegen Deutschland. Ross wurde von Ribbentrop engagiert, um seine Standardthesen propagandistisch umzusetzen. Es war offensichtlich schwierig, Ross „abzuwimmeln“. Daraufhin sei Dörries zu ihm, Ahrens, gekommen und habe gesagt: "Sie müssen sich absichern."

52 Vgl. Kiesinger, Jahre, S. 252.

${ }^{53}$ Dörries starb Ende der sechziger Jahre. Ahrens sei nach wie vor „persona grata“, erklärte ihm der Landesminister Baden-Württembergs, Seifriz, am Telefon im November 1966. Er, Ahrens, solle sich keine Sorgen machen: Man müsse auch einmal ein dickes Fell haben. Eine Kopie des Dokuments könne er allerdings nicht erhalten. $\mathrm{Er}$, Seifriz, habe Weisung, die Niederschrift von Dörries nicht aus der Hand zu geben. Vgl. Ahrens, Gespräch mit dem Verfasser, 9.8.1988. 
berale Koalition zu bilden ${ }^{54}$. Ohnmächtig mußte der Fraktionsvorsitzende mit ansehen, wie der parlamentarische Geschäftsführer der CSU, Leo Wagner, im Saal durch die hinteren Reihen ging und darauf achtete, daß die Abgeordneten der CSU den richtigen Namen auf die Wahlzettel schrieben, den Namen Kiesinger ${ }^{55}$.

Barzel schien nicht der Mann zu sein, der eine solche Niederlage einfach hinnehmen konnte. Er ließ den gewählten Kandidaten nicht im unklaren darüber, daß er das Kanzleramt für sich reserviert glaubte: „Sie haben sich in das Bett gelegt, das für mich gemacht war", sagte er Kiesinger offen ${ }^{56}$. Und es gab noch andere Hinweise, die darauf deuteten, daß der Gewählte um den endgültigen Sieg erst ringen mußte. Die Norddeutschen in der Fraktion hatten schon seit Monaten gegen ihn Stimmung gemacht, um die Chancen ihres Kandidaten im Falle des Sturzes der Regierung zu erhöhen. Der parlamentarische Geschäftsführer Will Rasner, ein enger Freund Barzels, sagte Anfang 1966 zu Heinrich Krone, Kiesinger dürfe Bonner Boden nicht mehr betreten ${ }^{57}$. Nach der Wahl ließ die Kampfansage an Kiesinger nicht lange auf sich warten. Barzel halte die Wahl Kiesingers für eine offene Fehlentscheidung, die sich zuungunsten der Union auswirken müsse, meldete der der SPD nahestehende Parlamentarisch-Politische Pressedienst am Wochenende $^{58}$. Der Hinweis verfehlte seine Wirkung nicht. Schon wenige Tage später spekulierte die Presse über eine vorzeitige Rückkehr Kiesingers nach Stuttgart. Am 16. November berichtete etwa die Frankfurter Rundschau, in der Union werde erwogen, den gewählten Kanzlerkandidaten wieder zurückzuziehen und Bundesinnenminister Paul Lücke mit der weiteren Verhandlungsführung zu betrauen. Man hoffe, durch ein Auswechseln der Kandidaten die Bildung einer SPD/FDP-Koalition vielleicht doch noch verhindern zu können. Kiesinger habe mit der öffentlichen Ankündigung, Strauß werde in seinem Kabinett einen Ministerposten bekommen, sich selbst die Tür zu SPD wie FDP verbaut. Und wörtlich hieß es: „In Bonn sah man am Dienstag Kiesingers Auftrag bereits als gescheitert an." ${ }^{\text {" } 9}$

In den nächsten Tagen überschlugen sich die Nachrichten. Am 18. November schrieb der Münchner Merkur, führende CSU-Politiker hätten der SPD ihre Bereitschaft erklärt, Kiesinger fallenzulassen, falls seine Kandidatur einer Großen Koalition im Wege stehe. Und einen Tag später berichtete Die Welt, maßgebliche Persönlichkeiten der CDU hätten die SPD buchstäblich gebeten, ,in den kommenden Verhandlungen mit der Union so zu taktieren, daß Kiesinger keine Mehrheit bekomme "60. Die Sache ging so weit, daß sich die Union gezwungen sah, sich noch einmal öffentlich für Kiesinger zu erklären.

Gefahr drohte auch durch die eigene Verhandlungskommission. Davor warnte zumindest der Generalsekretär der CDU. Die Kommission sei nicht mehrheitlich auf Kiesinger verpflichtet, behauptete sein schwäbischer Landsmann. Kiesinger sei in ihr weitgehend isoliert. Strauß müsse sich in den ersten Wochen vorwiegend im bayerischen Wahl-

54 Vgl. Barzel, Streit, Adenauer an Barzel vom 29.10.1966, S. 108. Zwei Tage nach dem Bruch der Koalition schrieb Adenauer: „Ich würde es sehr begrüßen, wenn Sie Bundeskanzler würden und wenn die bisherige Koalition fortgesetzt würde. “ Als Adenauer klar wurde, daß Kiesinger am Ende siegen würde, riet er dem Fraktionsführer, auf seinem Posten zu bleiben, sich nicht zur Wahl zu stellen. Er schätze im Moment dessen Wahlchancen sehr niedrig ein; vgl. Stuttgarter Nachrichten, 10.11.1966.

${ }^{55}$ Vgl. Barzel, Gespräch mit dem Verfasser, 10.6.1988.

${ }^{56}$ Kiesinger, Gespräch mit Baring, 12.5.1982.

${ }^{57} \mathrm{Vgl}$. Gerstenmaier, Streit und Friede, S. 536.

${ }^{58}$ Vgl. PPP, 219, Nachtrag, 11./12.11.1966, S. 1.

${ }^{59}$ Frankfurter Rundschau, 16.11.1966.

${ }^{60}$ Vgl. Münchner Merkur, 18.11.1966, und Die Welt, 19.11.1966. 
kampf engagieren und könne dadurch Kiesinger nicht zur Seite stehen. Durch diesen Umstand verschiebe sich das Gewicht innerhalb der Delegation zuungunsten Kiesingers, stellte Heck alarmierend fest. Das alles sei nur entstanden, weil er, der Bundesgeschäftsführer und wichtige Berater Kiesingers, nicht in die Kommission aufgenommen worden sei. Heck vermutete, daß ihn Barzel bewußt ausgeschlossen hatte. Dieser habe ihn für seinen Gegner gehalten. Der Fraktionsvorsitzende habe daher durchgesetzt, daß die Verhandlungskommission nach evangelisch-katholischer Parität besetzt wurde ${ }^{61}$. Neben Kiesinger bildeten Strauß als CSU-Vorsitzender und Barzel als Fraktionsführer die katholische Gruppe der Kommission. Daher blieb für Heck kein Platz übrig.

Für die evangelische Seite nahmen der stellvertretende Fraktionsführer, Peter-Wilhelm Brand, und der parlamentarische Geschäftsführer der CDU/CSU-Fraktion, Rasner, teil. Brand und Rasner stünden hinter Barzel und unterstützten dessen Ziele, warnte Heck Kiesinger. Falls Kiesinger etwa die Große Koalition anstrebe, könnten diese Mitglieder den Erfolg des Unternehmens leicht in Frage stellen. Heck wußte, wo die verwundbare Stelle bei den Koalitionsverhandlungen mit den Sozialdemokraten lag: beim Mehrheitswahlrecht. Man werde versuchen, prophezeite er, Kiesinger auf die Forderung nach dem Mehrheitswahlrecht festzulegen. Dazu mußten sich die Kommissionsmitglieder lediglich auf die Stimmung in den Kreisverbänden berufen. Heck selbst berichtete am 20. November 1966, am Tag der Bayernwahl, im Deutschlandfunk, daß die Orts- und Kreisvereine „recht verstimmt sind über die Art und Weise, wie nun die Freien Demokraten zum wiederholten Male eine Regierungskrise ausgelöst" hätten ${ }^{62}$. Und in den Zeitungen waren Stimmen wie diese zu lesen: Falls die eigene Kommission eine Koalition mit der SPD vorschlage und nicht sagen könne, „ob in Übereinstimmung mit der SPD das Wahlrecht geändert wird, dann dürfte sie auf Widerstand stoßen" ${ }^{63}$.

Heck behielt recht. Die Kommission einigte sich darauf, wie 1962 bei den Verhandlungen mit den Sozialdemokraten, ein neues Wahlrecht für unbedingt erforderlich zu erklären. Unbesorgt stimmte Kiesinger dem zu. Was außer Heck und ihm aber niemand wußte: Der stellvertretende SPD-Fraktionsführer Wehner hatte beim ersten Gespräch im kleinen Kreis zugesichert, daß die SPD das Mehrheitswahlrecht akzeptieren werde ${ }^{64}$. Doch Kiesingers vorsichtiger Berater hielt das für eine Falle. „Seien Sie vorsichtig, “ riet er seinem Landsmann, „die SPD kann kaum eine definitive Zusage geben!“ Eines war sicher: Die Festlegung auf das Mehrheitswahlrecht verbaute jede Aussicht auf eine Neuauflage der CDU/FDP-Koalition. Der Kanzlerkandidat hatte sich frühzeitig auf das Bündnis mit der SPD festgelegt.

\section{Rückkebr zur Kleinen Koalition? Kiesingers Zielsetzung als Kandidat}

Kiesinger hat seine Ausrichtung auf die Sozialdemokratie nach seiner Wahl zum Kandidaten im November 1966 später nicht mehr zugeben wollen, sondern seine Bemühungen um die Wiederzusammenführung der Kleinen Koalition bis zum letzten Verhandlungstag am 25. November hervorgehoben. In allen wissenschaftlichen Darstellungen wie auch in einer persönlichen Beschreibung der Ereignisse, die Kiesinger 1974 veröf-

61 Vgl. Heck, Gespräch mit dem Verfasser, 4.10.1988.

62 BPA, Heck im DLF, Interview der Woche, 20.11.1966, Anhang XI, S. 2.

${ }^{63}$ Rheinische Post, 25.11.1966. Auch Wehner faßte die Einführung des Mehrheitswahlrechts als Vorbedingung für eine Große Koalition auf; vgl. Terjung (Hrsg.), Der Onkel, Wehner in der ARD am 5.1.1980, S. 159.

${ }^{64}$ Vgl. Gerstenmaier, Streit und Friede, Krone vom 25./26.11.1966, S. 543. 
fentlichen ließ, ist bisher die Behauptung vertreten worden, daß bis zum letzten Verhandlungstag der Kommissionen eine Neuauflage der FDP-CDU/CSU-Koalition noch möglich gewesen sei ${ }^{65}$. Kiesinger schrieb 1974: „Die letzte Unterredung mit der Verhandlungskommission der FDP verlief ergebnislos, ohne daß sachliche Probleme aufgetaucht wären, die den Weg zu einer Koalition versperrt hätten. Man spürte: Die FDP wollte einfach nicht mehr." "66 Kiesinger hat auch später immer wieder betont, daß es ihm von Anfang an um die Kleine Koalition gegangen sei ${ }^{67}$. Die FDP habe aber keinen klaren Kurs erkennen lassen; niemand habe in diesen Tagen die Richtung der Partei bestimmt. Symptomatisch erschien ihm das Verhalten des Parlamentarischen Geschäftsführers HansDietrich Genscher, mit dem er sich am 25 . November vergeblich verabredet hatte. Genscher ließ Kiesinger im Bonner Gästehaus von Baden-Württemberg eine Stunde warten, bevor er telefonisch mitteilte, er habe eine dringende Verabredung und könne nicht kommen. Auch am nächsten Tag habe er wegen einer wichtigen Parteiversammlung in Nordrhein-Westfalen keine Zeit. Darauf mahnte Kiesingers Begleiter Scheufelen: „Herr Genscher, Sie müssen sich über eines klar sein, dann steht am Samstag, $24 \mathrm{Uhr}$, die schwarzrote Koalition. ${ }^{68}$ Aber Genscher habe das nicht glauben wollen.

Die Kontakte, die zwischen Wehner und dem Kandidaten der Union gleich nach seiner Wahl zum Kanzlerkandidaten der Union stattfanden, sind dagegen von Kiesinger nicht erwähnt oder beschrieben worden. Sein Verhältnis zur SPD in dieser Zeit hat er im dunkeln gelassen. Lediglich Mende, der FDP-Vorsitzende, verwies später auf die Bedeutung der persönlichen Gespräche zwischen dem stellvertretenden SPD-Vorsitzenden und dem Ministerpräsidenten. Die eigentliche Koalitionsabsprache, so Mende, habe am 21. November, dem Montag nach der bayerischen Landtagswahl, stattgefunden ${ }^{69}$, als sich Kiesinger und Wehner das politische Jawort gegeben hätten. Die FDP sei dadurch schon vor den Verhandlungen der Chance beraubt worden, an einer Regierung teilzunehmen.

Tatsächlich sprechen einige Fakten für die Annahme, daß Kiesinger sich schon bald nach seiner Wahl auf das Regierungsbündnis mit der SPD innerlich eingestellt und gegenüber Wehner darauf festgelegt hatte. Ganz allgemein schloß seine offene Haltung gegenüber den Sozialdemokraten seit 1949 eine solche Koalition nicht von vornherein aus, sondern rückte dieses Bündnis in den Bereich des Möglichen. Er betrachtete die SPD als notwendige, andere Kraft des Parlaments neben der Christdemokratischen Union. In seinen Memoiren erklärt er: Von den beiden großen Parteien habe 1949 abgehangen, was aus der Bundesrepublik werde. Falls CDU/CSU und SPD in einen unversöhnlichen Streit geraten wären, dann wäre künftiges Unglück für die Republik sicher gewesen ${ }^{70}$. Eine Zer-

${ }^{65} \mathrm{Vgl}$. Hildebrand, Erhard, S. 250 und 253, sowie Knorr, Entscheidungsprozeß, S. 76 und 88 f. Beide verweisen auf die Absicht Kiesingers bei seiner Ankunft in Bonn, die Koalition mit der FDP zu erneuern. Erst die letzte Sitzung der Kommissionen von CDU/CDU und FDP hätte die Entscheidung zugunsten der Großen Koalition gebracht. Hildebrand meint, daß bis zum 25.11.1966 eine Wiederauflage "noch im Bereich des Möglichen“ gewesen sei. Knorr weist auf eine Vorentscheidung hin, die am 24.11.1966 gefallen sei, als CDU/CSU und SPD zu einer weitgehenden Einigung in den Fragen der Wirtschafts-, Finanz- und Sozialpolitik gekommen seien.

${ }^{66}$ Kiesinger, So war es, I, Bild am Sonntag, 17.11.1974.

${ }^{67} \mathrm{Vgl}$. Scheufelen, Gespräch mit dem Verfasser, 27.11.1987. Noch vier Monate vor seinem Tod war Kiesinger sich mit Scheufelen darüber einig. Beide besprachen sich aus Anlaß des bevorstehenden Gesprächs Scheufelens mit dem Verfasser. Scheufelen solle deutlich machen, schlug Kiesinger vor, daß er eine Koalition mit der FDP angestrebt habe.

${ }^{68}$ Ebenda.

${ }^{69}$ Vgl. Mende, Die FDP, S. 218.

${ }^{70}$ Vgl. Kiesinger, Jahre, S. 365. 
splitterung des Parteiensystems, wie es in der Weimarer Zeit geschehen war, dürfe es nicht wieder geben. Im ersten Bundestag hielt der junge Abgeordnete daher beispielsweise die Wahl eines Bundespräsidenten für notwendig, den SPD und CDU/CSU gemeinsam trugen. Aber er setzte sich vergeblich für diesen Vorschlag ein.

Als außenpolitischer Experte seiner Fraktion entwickelte Kiesinger in den fünfziger Jahren gute Beziehungen zu Führern der Oppositionspartei. Mit Fritz Erler beispielsweise verband ihn ein freundschaftliches Verhältnis. Sein liebster Diskussionspartner, bekannte Erler 1965, sei Kiesinger. Gemeinsam traten sie bei Wahlkundgebungen des jeweils anderen auf ${ }^{71}$. Auch in den Bundestagsgremien - Kiesinger hatte den Vorsitz des Außenpolitischen Ausschusses und des Vermittlungsausschusses inne - kam es zur engen Zusammenarbeit mit SPD-Parlamentariern, vor allem mit Wehner. Die Meinung scheint nicht abwegig, Adenauer habe deshalb gezögert, den begabten Schwaben in ein Ministeramt zu berufen, weil dieser eine zu große Bereitschaft zur überparteilichen Verständigung gezeigt habe. Erich Strätling, der spätere erste Botschafter in Bukarest, war Mitte der fünfziger Jahre Verbindungsmann des Auswärtigen Amtes zum Auswärtigen Ausschuß. Kiesinger, so sein Eindruck, habe sich, manchmal auf Kosten der CDU-Position, in vielen Fragen mit der SPD geeinigt $\mathrm{t}^{72}$.

Als Kiesinger 1958 die Bundeshauptstadt verließ, um in Stuttgart für das Amt des Ministerpräsidenten zu kandidieren, schickte ihm Wehner ein Telegramm, das in seiner verkürzten Fassung berühmt geworden ist: „Bonn wird ärmer. Wehner.“ Dazu hatte der parlamentarische Kollege geschrieben, er verstehe gut, daß Kiesinger jetzt nach BadenWürttemberg gehe, um in Bonn nicht mehr an den "Gladiatorenkämpfen" teilnehmen zu müssen. „Er hat mir das Wort, Gladiatorenkämpfe‘ besonders positiv angerechnet, der Herr Kiesinger", meinte Wehner später ${ }^{73}$. Das Verhältnis zu Wehner verlor auch in Stuttgart für Kiesinger nicht seine Bedeutung. Als der Ministerpräsident die SPD 1960, nach dem Gewinn der absoluten Mehrheit im „Ländle“, aus der gemeinsamen Regierung ausschloß und eine christlich-liberale Regierung bildete, verfaßte er einen Entschuldigungsbrief an den stellvertretenden SPD-Fraktionsvorsitzenden in Bonn ${ }^{74}$. Im Dezember 1962 soll Kiesinger bereits mit der Bildung einer Großen Koalition einverstanden gewesen sein, nachdem die FDP-Minister infolge der Spiegel-Affäre das Kabinett verlassen hatten ${ }^{75}$. Aber dazu kam es nicht; wieder bildeten FDP und CDU/CSU ein Regierungsbündnis. Als vier Jahre später diese Koalition in die Krise geriet, dachte Kiesinger offenbar auch an die Bildung einer Großen Koalition. Während eines Telefonats gab Kiesinger dem Tübinger Politologen Theodor Eschenburg recht, als dieser behauptete, die Finanzkrise werde ins Unermeßliche steigen, falls sich die beiden großen Parteien

71 Vgl. ebenda, S. 371, und Vorstand der SPD (Hrsg.), Bestandsaufnahme, S. 90-93; von seinem Krankenbett aus schrieb der Fraktionsführer im November an den SPD-Parteivorsitzenden, er plädiere für die Bildung einer Großen Koalition. Kiesinger schickte am 1.12.1966 ein Dankes- und Genesungstelegramm an Erler, das dieser wenig später beantwortete: „[...] Für Ihr telegrafisches Gedenken am Tage Ihrer Wahl danke ich Ihnen besonders herzlich. Es hat mir wohl getan. Mit den besten Grüßen und Wünschen Ihr ergebener [...]." (AdKASt, Kiesinger I - 226, D/IV.6, A 003, Erler an Kiesinger vom 6.12.1966). Kiesinger schrieb zurück: „[...] ich danke Ihnen für Ihre guten Wünsche, die Sie mir zum Antritt meines neuen Amtes übermittelt haben herzlich. Sie wissen, wie gern ich Sie jetzt an meiner Seite gehabt hätte. [...] In alter Verbundenheit stets Ihr [...].“ (AdKASt, Kiesinger I - 226, D/IV.6, Kiesinger an Erler vom 23.12.1966). Erler starb am 22.2.1967.

72 Vgl. Stamp, Gespräch mit dem Verfasser, 30.11.1987. Oberst Stamp war der Verbindungsmann im Bundeskanzleramt zum Verteidigungsministerium.

${ }^{73}$ Wehner, Gespräch mit Bruhns, 15.10.1973, S. 7.

${ }^{74}$ Vgl. Der Spiegel, 5.12.1966, S. 32.

75 Vgl. Mende, Wende, S. $67 \mathrm{f}$. 
weiterhin gegenseitig wie im Wahlkampf bekämpften. Union und SPD betrieben eine Politik der Geldversprechungen, um die Wählergunst zu gewinnen. Wenn beide Parteien aber zusammenarbeiteten, könnten sie sich gegenseitig kontrollieren und die Finanzausgaben einschränken, meinte Eschenburg. Kiesinger ging darauf ein und erklärte: „Sie haben recht. Das einzige, was jetzt hilft, ist die Große Koalition.“76

Im November 1966 lief die Entwicklung schnell auf das Bündnis zwischen den beiden großen Parteien zu. Zwar äußerte sich Wehner öffentlich zurückhaltend zur Entscheidung der Unionsfraktion, Kiesinger zum Kandidaten zu küren. Mit der Nominierung seien die Chancen für die Entstehung einer Großen Koalition weder gestiegen noch gesunken, erklärte er gegenüber dem $Z D F$ am 10. November. Und im Deutschlandfunk äußerte er sich sogar skeptisch: „Herr Kurt Georg Kiesinger wird es nicht leicht haben, in dem ihm ungewohnt gewordenen Gelände der Bundesrepublik sich zurechtzufinden. Ob er imstande sein kann, die ihm von der Mehrheit der Fraktion der CDU/CSU auferlegte Arbeit zu erfüllen, steht dahin. " 77

Dennoch konnten sich die beiden im ersten persönlichen Gespräch, das noch vor den offiziellen Verhandlungen der Kommissionen diskret in einem Bonner Gästehaus der Vertretung Nordrhein-Westfalens stattfand ${ }^{78}$, schnell über die wesentlichen Voraussetzungen einer Großen Koalition einigen. Natürlich mußte Wehner dort die Forderung akzeptieren, daß Strauß ein Ministeramt erhalten sollte. Und welches Amt sollte der SPDVorsitzende übernehmen? Man könne davon ausgehen, versicherte Wehner, daß dieser nicht Außenminister werden wolle, sondern sich mit einem kleineren Posten zufriedengeben werde. Brandt habe davon gesprochen, vielleicht das Wissenschaftsministerium zu übernehmen. Das würde ihm erlauben, sich nebenher stärker seiner Parteiarbeit zu widmen.

Kiesinger wurde durch die Übereinstimmung mit Wehner in den wesentlichen Fragen frühzeitig von der Möglichkeit einer Großen Koalition überzeugt. Das lag vor allem am Geschick des stellvertretenden SPD-Parteivorsitzenden, der taktisch sehr klug mit dem Christdemokraten umging. Wehner schmeichelte dem Ministerpräsidenten, sprach ihn bereits zu diesem frühen Zeitpunkt mit „Herr Bundeskanzler“ an. Über die eigene Parteiführung sprach er sich abschätzig aus. Insgesamt vermittelte Wehner eine Atmosphäre künftiger Koalitionszusammenarbeit, wie sie Kiesinger zusagte. Je länger die Verhandlungen dauerten, desto sicherer wurde der CDU/CSU-Kanzlerkandidat in der Überzeugung, nur die SPD käme als Partner in Frage. Am Donnerstag, dem 24. November, kurz bevor die Fraktionen von CDU/CSU und SPD zur entscheidenden Sitzung zusammentrafen, vertraute er Kempski an: „Der Zustand unseres Staates macht die Große Koalition zwingend. Ich bin deshalb für die Große Koalition, seit ich den Auftrag zur Regierungsbildung angenommen habe. “79

Schon frühzeitig hat sich Kiesinger also für das Regierungsbündnis mit den Sozialdemokraten entschlossen. Aus welchem Grunde beharrte er später darauf, daß es ihm vor-

\footnotetext{
${ }^{76}$ Eschenburg, Gespräch mit dem Verfasser, 7.12.87.

7 BPA, 14.11.1966, Anhang XI, S. 1, und Pressestelle der SPD-Fraktion, Nr. 479, 10.11.1966, S. 1.

${ }_{78} \mathrm{Vgl}$. Baring, Machtwechsel, S. 130. In einem abgelegenen Hause in der Argelanderstraße, das dem Land Nordrhein-Westfalen als festes Bonner Gästequartier diente, so Baring, hätte sich Wehner, begleitet vom getreuen Jürgen Weichert (SPD), mit Johannes Schauff und Heck heimlich zu koalitionsentscheidenden Vorsondierungen und personellen Absprachen in den kritischen Wochen mehrfach getroffen. Weichert erklärte später, um den 17./18.11.1966 sei die Große Koalition „fast komplett" gewesen; vgl. Weichert, Gespräch mit Baring, 19.5.1977.

79 Süddeutsche Zeitung, 26.11.1966.
} 
wiegend um die Wiederherstellung der alten Koalition mit den Liberalen gegangen sei? Die Beantwortung dieser Frage hat mit dem Vorwurf zu tun, die Vernachlässigung der Liberalen durch den Kanzler in der Zeit der Großen Koalition sei dafür verantwortlich, daß es nach der Wahl von 1969 nicht zu einer Neuauflage der Kleinen Koalition gekommen sei und die Union in die Opposition gehen mußte. Die Kritik an Kiesingers nachlässiger Haltung gegenüber den Liberalen ab 1966 wurde von FDP-Mitgliedern, die der CDU nahestanden, wie etwa Mende, aber auch von Walter Scheel bestätigt. Vor allem aber die eigene Partei hielt es für einen Fehler, daß der Kanzler sich nicht um Kontakte zur FDP bemühte. Heck, der Vertraute Kiesingers und spätere Generalsekretär der CDU, klagte, es habe nur ein Gespräch zwischen dem Kanzler und dem Vorsitzenden Scheel gegeben. Und, was noch schlimmer war: Man habe Kiesinger angemerkt, daß er es aus Routine geführt habe ${ }^{80}$. Scheufelen riskierte einen handfesten Krach, als er im Frühjahr 1969 dem Kanzler klarmachte, er solle nicht die FDP vergraulen, indem er weiterhin auf die Einführung des Mehrheitswahlrechts dränge ${ }^{81}$.

Von all dem wollte Kiesinger später nichts mehr wissen. Er entwickelte eine starke Neigung, seine ursprünglichen Absichten zu verschleiern oder umzudeuten. In der Koalitionsfrage konnte ihm das um so leichter gelingen, als über die heimlichen Kontakte mit der SPD nie ein Wort an die Öffentlichkeit drang. Seine Erklärung erschien daher durchaus glaubwürdig, er habe bis zuletzt vergeblich auf eine Zusage der FDP gewartet. Dann habe er mit der SPD abgeschlossen. Kiesinger konnte das behaupten, weil sein früheres Engagement für die Liberalen, etwa die Aufnahme in die Regierung Baden-Württembergs, diese Aussage stützte und glaubhaft erscheinen ließ. Er konnte es sich auch weiterhin leisten, seine Bemühungen um die FDP herauszustreichen und die Absprachen mit Wehner einfach zu unterschlagen.

Dabei sprach im Herbst 1966 vieles für das Bündnis von SPD und CDU/CSU. Die Übereinstimmung in sachlichen Fragen, vor allem im Hinblick auf die Überwindung der Rezession und den damit zusammenhängenden sozialen Fragen, ließ die Bildung dieser Koalition ratsam erscheinen - ganz anders übrigens 1969, als die größeren Gemeinsamkeiten zwischen SPD und FDP in der Ost- und Deutschlandpolitik zum Tragen kamen. Nicht nur aus diesem Grunde drängte Wehner seine Partei im November 1966 entschlossen in die Koalition mit der Union.

\section{Wehner treibt seine Fraktion in die Große Koalition}

Noch entschlossener als Kiesinger arbeitete Wehner seit langer Zeit auf die Große Koalition hin. Von der FDP hielt der stellvertretende SPD-Vorsitzende seit Beginn der sechziger Jahre nicht mehr viel. In den fünfziger Jahren hatte er noch gehofft, die Liberalen würden unter ihrem Vorsitzenden Reinhold Maier eines Tages eine SPD-FDP-Koalition bilden, so wie Maier sie 1952/53 als Ministerpräsident in Baden-Württemberg geführt hatte ${ }^{82}$. Aber seit der Übernahme des Parteivorsitzes durch Mende suchte die Partei ausschließlich das Bündnis mit der CDU/CSU und wurde als eine Art „Nebenregierungspartei“ gesehen. Die FDP, so sagte Wehner mit seinem beißenden Spott im Februar 1966, sei wie die Sahne, die zur Schokoladentorte gehöre. Und er fügte hinzu: In Deutsch-

${ }^{80}$ Vgl. Heck, Gespräch mit Dreher, 6.12.1983, S. 2.

81 Vgl. Scheufelen, Gespräch mit dem Verfasser, 27.11.1987.

${ }^{82}$ Vgl. Baring, Machtwechsel, S. 46. 
land werde ja Sahne zur Torte geschätzt ${ }^{83}$. Der Sinn der Liberalen bestehe vor allem darin, erklärte er acht Monate später, unzufriedene CDU-Wähler aufzufangen und sie dadurch der CDU wieder zuzuführen. Das sei der Grund, warum sie neben der CDU mitregieren dürfe. FDP und CDU/CSU gehörten zum selben Lager. Für die SPD ergebe sich als Konsequenz daraus: „Die Sozialdemokraten haben diese Kombination zu behandeln, als wäre es eine Partei. " 84

Der Bruch der Regierung Erhard am 27. Oktober markiert jenen Zeitpunkt, auf den Wehner und die Sozialdemokratische Partei Deutschlands lange gewartet hatten. Seit dem Godesberger Programm 1959 und dem Bekenntnis der Partei zum außenpolitischen Fundament von Adenauers Weststaat durch Wehners Rede vom 30. Juni 1960 versuchte die SPD, für breite Wählerschichten attraktiv zu werden. Als Volkspartei glaubte die Führung der traditionsreichen Arbeiterpartei, die Union aus der Regierung verdrängen zu können. Aber der Erfolg blieb lange aus. 1961 reichte es nur zu 36,2 Prozent der Stimmen, und 1965 erzielte Erhard das zweitbeste Ergebnis in der Geschichte der CDU/CSU (47,6 Prozent); die SPD blieb - den Umfragen und Erwartungen entgegen - knapp unter der 40-Prozent-Marke und lag bei 39,3 Prozent. Da die sozialdemokratische Regierungsbeteiligung nicht auf direktem Weg durch Wahlen erreicht werden konnte, mußte sie indirekt angestrebt werden. 1962 wäre mit Adenauers Hilfe beinahe eine Große Koalition zustande gekommen. Die Grundlagen waren bereits zwischen Wehner und den beiden Vertretern der Union, Lücke und Karl Theodor Freiherr von und zu Guttenberg, ausgehandelt, als sich die SPD-Bundestagsfraktion dem Vorhaben versagte. Die Abgeordneten nahmen es ihrer Führung übel, vor vollendete Tatsachen gestellt worden zu sein.

Trotzdem blieb das Thema Große Koalition auch über die folgenden Jahre aktuell. Prominente Unionsmitglieder befürworteten ein Regierungsbündnis der beiden großen Parteien - aus Opposition gegen den eigenen Bundeskanzler Erhard oder aus dem Wunsch nach größerer innenpolitischer Stabilität der noch jungen parlamentarischen Demokratie. Eine Reihe wichtiger Gesetzesvorhaben, wie die Notstandsverfassung oder das Mehrheitswahlrecht, konnte ohne eine Zweidrittelmehrheit im Bundestag nicht durchgebracht werden. Adenauer unterstrich daher in einem Aufsatz kurz vor der Wahl von 1965 die Notwendigkeit einer solchen Koalition ${ }^{85}$. Daneben galten auch Bundestagspräsident Gerstenmaier und Bundespräsident Heinrich Lübke, der Wehner persönlich schätzte, als Befürworter eines solchen Regierungsbündnisses. Gerstenmaier wäre gerne schon 1961 Chef einer Allparteienregierung geworden, und bei dem ehemaligen Abgeordneten des preußischen Landtages Lübke war es die Erinnerung an die Weimarer Koalition als stabilisierender Faktor der ersten deutschen Republik, die eine entscheidende Rolle für sein Engagement zugunsten der Großen Koalition spielte. Als die christlich-liberale Regierung 1966 immer schneller an Popularität verlor und mit einer erstmals in der Bundesrepublik auftretenden Rezession nicht fertig wurde, schien der Augenblick für das Regierungsbündnis zwischen den beiden großen Parteien gekommen zu sein. Die Union hatte sich in eine Lage manövriert, aus der sie ohne die Hilfe der SPD nicht wieder herauskam.

\footnotetext{
${ }^{83} \mathrm{Vgl}$. Stern, 2.2.1966.

${ }^{84}$ Gaus, Staatserhaltende Opposition, S. 102.

${ }^{85}$ Vgl. Adenauer, Möglichkeiten einer Koalition, S. 13-17.
} 


\section{Webners Kurs und sein Einfluß auf die Fraktion}

Wehner hatte die ihm von der eigenen Fraktion erteilte Lektion von 1962 nicht vergessen. Auf die Situation im Herbst 1966 angesprochen, traf er noch Jahre später die Feststellung, sein Bestreben sei gewesen, der Fraktion die freie Entscheidung über die Bildung einer Koalition „mit welcher Partei auch immer“ zu überlassen. Sein einziger Grundsatz „hinsichtlich des Wie-Führens und Wie-Verbindlichmachens" sei gewesen, daß die Beschlußkörperschaften der Sozialdemokraten, also Parteivorstand, Parteirat und Bundestagsfraktion, bis zum vorletzten Tag für eine Entscheidung frei waren ${ }^{86}$. Einschränkend gab er allerdings zu verstehen, daß die Mitglieder der sozialdemokratischen Verhandlungskommission die Aufgabe hatten, die Richtung anzugeben. Die Kommission habe der Fraktion „immer sagen müssen, in welchen Punkten die einen [...] entgegenkommender waren " als die anderen.

Wehner läßt in dieser Darstellung den Einfluß unerwähnt, den er selbst im Herbst 1966 auf die Partei ausübte. Von allen SPD-Führern besaß sein Wort das größte Gewicht. Die Abgeordneten schauten auf ihn - aus Bewunderung und auch aus Respekt. Damals nahm er jene Stellung ein, in die 1969, in seiner Art allerdings verbindlicher, Brandt hineinwuchs. Er profitierte von einer günstigen Personalkonstellation: Erich Ollenhauer, der langjährige Parteivorsitzende, war 1964 gestorben. Erler, der Fraktionsvorsitzende und bedeutende außenpolitische Experte der Partei, lag todkrank in einer Freiburger Klinik. Brandt selbst regierte als Bürgermeister in Berlin. Der SPD-Vorsitzende trug lange an der unerwarteten Bundestagswahlniederlage von 1965. Ohne ein Wort zu sagen, hatte er damals das Handtuch geworfen und die Partei sich selbst überlassen. Helmut Schmidt war noch zu jung und erst seit ein paar Monaten wieder Abgeordneter im Bundestag. Auch er hatte bei der Wahl zum Landesvorsitz in Hamburg eine Niederlage einstecken müssen, an der Wehner nicht schuldlos gewesen sein soll. Aber Wehners Einfluß auf seine Fraktion im Herbst 1966 war nicht nur einer glücklichen Personalkonstellation zu verdanken. Er besaß auch die stichhaltigsten Argumente. Zur Bildung einer Großen Koalition, davon war er überzeugt, gab es damals keine Alternative. Und dieses Bündnis konnte nur unter einem Bundeskanzler Kiesinger zustande kommen.

Von Beginn an ließ Wehner keinen Zweifel daran, daß er auf den Kanzlerkandidaten Kiesinger setzte. Nur mit Kiesinger werde es eine Große Koalition geben, erklärte er seinen Parteifreunden. Seine Argumentation war einfach: In der Unionsfraktion besaß nach Kiesinger Schröder die Mehrheit, und ein Kanzler Schröder war nur in einer Neuauflage der christlich-liberalen Koalition denkbar. Vor der eigenen Fraktion wandte sich Wehner daher am 26. November 1966 an diejenigen, die kurzfristig mit Unterstützung der FDP einen sozialdemokratischen Kanzler wählen wollten, auch wenn diese Koalition nur über eine hauchdünne Mehrheit verfügen sollte. „Personelle Alternativen sind nach wie vor möglich“, sagte er, „wenn man nach wie vor glaubt, es gäbe noch die Chance für ein konstruktives Mißtrauensvotum. Ich meine das gar nicht polemisch, sondern sage es nur, um die Situation klarzustellen. Nach einem gescheiterten sozialdemokratischen Bundeskanzler wäre Schröder die nächste Figur, und dies ist gleichbedeutend mit der Wiederherstellung der alten FDP-CDU/CSU-Koalition. “87

Die Fraktion stimmte schließlich der Bildung der Großen Koalition zu. Es bedurfte allerdings harter Arbeit, viel Geduld und Geschick, bis der stellvertretende Fraktions-

86 Terjung (Hrsg.), Der Onkel, Wehner in der ARD am 5.1.1980, S. 157.

${ }^{87}$ AdsD, Protokolle interner Sitzungen der Führungsgremien, SPD-Fraktionssitzung vom 26./27.11.1966, S. 23. 
führer „seine“ Abgeordneten auf den Kurs des Bündnisses mit der Union gebracht hatte. Eine vielleicht schwierigere Aufgabe bestand für Wehner darin, die Union von der Notwendigkeit des Bündnisses mit der SPD zu überzeugen. Die strategische Begabung Wehners hat sich in keiner anderen Situation so deutlich gezeigt wie in dieser Lage. Im November 1966 galt es, einerseits die eigene Partei in seine Richtung zu führen, andererseits die trotz des Bruches mit der FDP noch weiter amtierende Regierungspartei, die $\mathrm{CDU} / \mathrm{CSU}$, in eine Koalition mit der SPD zu zwingen.

\section{Die Union mürbe machen}

Am 2. November, nur wenige Tage nach dem Ausstieg der FDP aus der Regierung, legten die Sozialdemokraten einen Katalog politischer Zielsetzungen vor, der Grundlage einer künftigen Bundesregierung unter sozialdemokratischer Beteiligung sein sollte. Das Acht-Punkte-Programm enthielt vier außenpolitische und vier wirtschaftspolitische Grundsätze. Im außenpolitischen Bereich forderte die SPD nicht sehr viel mehr als das, was bereits die CDU/CSU selbst verfolgte oder zumindest diskutierte: erstens die Neubelebung des Verhältnisses zu Frankreich und den USA, zweitens den Verzicht auf den "Ehrgeiz auf atomaren Mitbesitz", also die Zustimmung zum Atomwaffensperrvertrag, drittens die Aufnahme diplomatischer Beziehungen zu den Staaten Osteuropas, „die dafür keine unannehmbaren Bedingungen" stellten, viertens die Suche nach Kontakten zwischen Behörden in beiden Teilen Deutschlands ${ }^{88}$. Bis auf den Sperrvertrag handelte es sich alles in allem um relativ moderate Forderungen. Sie wiesen darauf hin, daß das Programm an die Adresse der Christdemokraten gerichtet war: Die SPD stellte ihr Programm auf die bisherige Regierungspartei ab. Am Schluß der öffentlichen Vorstellung der acht Punkte im Bundeshaus rief Wehner aus: „Wir wollen nicht mitregieren, wir wollen regieren, und der Tag wird kommen, wo wir regieren." ${ }^{99}$

Kempski ist der aggressive Ton im Ohr geblieben: Wehner habe beinahe geschrien, so als müsse er sich selbst Mut machen. Die Äußerung vom 2. November sollte vermutlich Hinweis und Warnung an die CDU/CSU zugleich sein. Hinweis, denn damit sagte der Sozialdemokrat: Auch in einer Großen Koalition werde man sich nicht als Juniorpartner behandeln lassen; Warnung, denn gleichzeitig machte er deutlich, es sei auch eine andere Regierungskonstellation für die SPD - ohne die Union - nämlich mit der FDP, denkbar. Zwar glaubte Wehner nicht an diese Möglichkeit. Aber in den folgenden Tagen brachte die SPD-Führung das Instrument eines Mißtrauensvotums gegen Erhard, der ja weiterhin als Kanzler einer Minderheitsregierung fungierte, ins Gespräch und verlieh somit ihrem Anspruch Nachdruck, die Regierung zu übernehmen. Rein rechnerisch konnte der Bundestag mit vereinten Kräften von SPD und FDP dem Kanzler das Mißtrauen aussprechen. Insgesamt verfügten beide Parteien über eine Mehrheit von sechs Mandaten (251 Abgeordnete gegenüber 245 von CDU/CSU). Allerdings bedarf es nach Art. 67 des Grundgesetzes beim konstruktiven Mißtrauensvotum eines Kanzlerkandidaten der Antragsteller, der mit neuer Mehrheit eine Regierung bilden muß. Dazu war aber die Mehrheit von SPD und FDP zu keinem Zeitpunkt im November 1966 in der Lage.

Während Wehner mit dem Einsatz eines Mißtrauensvotums drohte, das er aber nicht hätte durchführen können, überlegte er, durch welche Maßnahmen die Position der Union weiter erschüttert werden konnte. Bemühungen der Union um ein Regierungsbündnis mit der SPD gab es nicht, obwohl die Regierung Erhard nur über eine Minderheit im

\footnotetext{
${ }^{88}$ Vorstand der SPD, Bestandsaufnahme, S. $19 \mathrm{ff}$.

${ }^{89}$ Süddeutsche Zeitung, 7.11.1966.
} 
Parlament verfügte. Nach Wehners Meinung mußte den anscheinend noch nicht genug verunsicherten Mitgliedern von CDU/CSU deutlich vor Augen geführt werden, daß sie die Mehrheit verloren hatten. Sein Mißtrauen gegen die scheinbar arrogante Staatspartei war groß. In einem Gespräch mit Günter Gaus, das nur wenige Wochen zuvor geführt worden war, hatte der Sozialdemokrat erklärt, die Union weigere sich, demokratischen Regeln auch dann zu folgen, wenn dies nicht zu ihrem unmittelbaren Vorteil ausschlage. „Alle Wortbekenntnisse der führenden CDU-Leute zur Demokratie sind bis heute - nehmen Sie das ganz so, wie ich das sage - Schall und Rauch, solange sie sich nämlich nicht daran gewöhnen können, daß zur Demokratie auch der Wechsel der Regierung gehört." Das sei ganz einfach die Gewöhnung der Partei an eine „Erbhofpolitik“ erklärte der Oppositionspolitiker diese Haltung und ergänzte: „Hier wird die CDU umlernen müssen.“90

Diese letzte, selbstbewußte Ẩ $u$ erung war auf die politische Situation in NordrheinWestfalen gemünzt, wo die Union im Juli 1966 eine herbe Niederlage hatte hinnehmen müssen und zusammen mit der FDP im Parlament nur noch über die knappste Mehrheit von einem Mandat verfügte. Erbittert registrierten die Sozialdemokraten, daß die Landesregierung trotz des Vertrauensentzugs der Wähler so weiterregierte, als ob nichts geschehen sei. Jetzt, nur drei Monate nach den Wahlen in Nordrhein-Westfalen, dachte der stellvertretende SPD-Fraktionsführer über Wege nach, der Union ihre Ohnmacht spüren zu lassen. Sie sollte auf unsanfte Weise an die Tatsache gemahnt werden, daß sie künftig auf die SPD angewiesen war. Da ein konstruktives Mißtrauensvotum für Wehner ausschied - eine Regierungskoalition mit der FDP lehnte er ab -, verfiel er auf den Gedanken, einen Antrag auf „Stellung der Vertrauensfrage“ einzubringen". Das war etwas Neues, eine von den Verfassungsvätern nicht vorgesehene Variante des Art. 68 im Grundgesetz. Danach kann der Kanzler den Bundestag auflösen und Wahlen anberaumen, falls ihm der Bundestag das Vertrauen versagt. Mit dem Antrag kehrten die Oppositionsparteien den Sinn des der Exekutive zur Verfügung stehenden Instrumentes um. Natürlich konnten sie den Kanzler nicht zwingen. Der Zweck lag vielmehr darin, die existierenden neuen Mehrheitsverhältnisse deutlich zu machen und den Abgeordneten von CDU/CSU zu zeigen, daß sie sich im Parlament in der Minderheit befanden.

Die Union suchte zunächst nach rechtlichen Mitteln, um den Vorgang zu blockieren. Sie bezweifelte, ob das Ganze verfassungskonform sei. Nach dem Grundgesetz gilt die Vertrauensfrage lediglich als Instrument des Kanzlers. Das Gegenstück, die Waffe der Opposition, ist das konstruktive Mißtrauensvotum. Wenn die Sozialdemokraten dazu nicht in der Lage seien, so argumentierte man, dann solle man die Sache besser auf sich beruhen lassen. Aber von diesen Argumenten ließ sich die SPD nicht beeindrucken. Nachdem die Experten der CDU/CSU keine Möglichkeit sahen, den Antrag mit juristischen Mitteln zu verhindern, versuchten führende Unionspolitiker in persönlichen $\mathrm{Ge}$ sprächen, Wehner umzustimmen. Bundestagspräsident Gerstenmaier warnte vor den möglichen Folgen, die ein solcher Antrag auf kommende Koalitionsverhandlungen haben könne. In der Fraktionssitzung am 8. November berichtete Wehner über sein Gespräch vom Vortag: Gerstenmaier habe angedeutet, daß „eine Sachdebatte über diesen Antrag unter Umständen die Geneigtheit von Teilen der CDU, mit der SPD Koalitionsver-

${ }^{90}$ Gaus, Staatserhaltende Opposition, S. 101.

${ }^{11}$ Terjung (Hrsg.), Der Onkel, Wehner in der ARD am 5.1.1980, S. 156; „[...] also gab es die zweitbeste Lösung, um sie so zu nennen, die habe ich an einem Montag, da mir keiner helfen wollte, herausgetüftelt und zu Papier gebracht; die war einwandfrei, nämlich ein Antrag mit genauer Begründung, ohne daß man ihn antasten konnte, daß er die Vertrauensfrage stellen soll. Man konnte ihn dazu nicht zwingen, aber der Antrag konnte beschlossen werden." 
handlungen zu führen, erschweren könne" ${ }^{\text {"92 }}$. Wehners Ziel sei schon erreicht, soll der Bundestagspräsident deutlich gemacht haben. Er habe auf eine Entschließung des Präsidiums der CDU verwiesen, die dem Gespräch vorausgegangen war. Darin habe, so Gerstenmaier, das Präsidium im Einvernehmen mit der Fraktion den Vorschlag gebilligt, Verhandlungen mit beiden Parteien, also auch der SPD, aufzunehmen.

Aber Wehner besaß noch andere Informationen. Von Lübke erfuhr er, daß über das Kommuniqué im Präsidium nicht einmal abgestimmt worden war. Lübke beschrieb dem Sozialdemokraten folgenden Hergang der CDU-Präsidiumssitzung: Schröder und Theodor Blank, der stellvertretende Fraktionsvorsitzende ${ }^{93}$, hätten es kategorisch abgelehnt, mit der SPD überhaupt zu verhandeln. Der Parteivorsitzende Erhard sei völlig unentschlossen gewesen, ob er solchen Verhandlungen zustimmen oder sie ablehnen sollte ${ }^{94}$. Und seither, meinte Wehner gegenüber den eigenen Abgeordneten, habe auch niemand der SPD ein Angebot für Verhandlungen unterbreitet. Es seien lediglich Einzelpersonen an die SPD herangetreten, um die Lage zu sondieren. Sie hätten nur für sich selbst gesprochen und nicht für die Fraktion oder eine Mehrheit in der Union. Aus diesem Grund hielt Wehner an seinem Vorhaben fest. Er sähe keine Möglichkeit, den Antrag zurückzuziehen, erklärte er Gerstenmaier. Aber er sei auch nicht an einer hitzigen Debatte interessiert und werde daher mäßigend auf seine Fraktion einwirken, fügte er versöhnlich hinzu.

Nun lag der Erfolg des Unternehmens in den Händen der Liberalen. Nur wenn sie geschlossen für den Antrag votierten, konnte die Union überstimmt werden. Am Abend vor der Abstimmung beriet die FDP-Fraktion in einer fünfstündigen Debatte, bis sich eine Mehrheit für die Zustimmung zum SPD-Antrag ausgesprochen hatte. Mit $255 \mathrm{zu}$ 246 Stimmen wurde er am 8. November tatsächlich durch den Bundestag angenommen. Damit konnte die SPD und mit ihr Wehner den ersten Triumph über die Union verbuchen.

\section{„Liquidation einer gescheiterten Politik“ - Webner verpflichtet die Fraktion auf seine Strategie}

Nach dem Abstimmungssieg wurden in der SPD Hoffnungen geweckt, beide Parteien könnten Erhard stürzen und einen Kanzler wählen, wenn auch nur für einen kurzen Zeitraum, der durch Neuwahlen abgeschlossen werden sollte. Nach einem Mißtrauensantrag würden SPD und FDP einen Sozialdemokraten zum Kanzler wählen. Dieser sollte anschließend die Vertrauensfrage stellen und, da er diesmal keine Mehrheit erhalten würde, den Bundespräsidenten zur Auflösung des Parlaments auffordern. Vermutlich würde die SPD vom desolaten Zustand der CDU/CSU profitieren und die Wahl gewinnen. Die Enttäuschung unter den SPD-Abgeordneten war daher groß, als Brandt am 9. November die Fraktion von einem ersten Zusammentreffen mit Führern der FDP unterrichtete und mitteilte, er habe in dem Gespräch mit den Liberalen den Eindruck gewonnen, daß

\footnotetext{
92 AdsD, Protokolle, Fraktionssitzung vom 8.11.1966, S. 2.

${ }^{93}$ Theodor Blank (1905-1972) war bis 1950 Beauftragter der Bundesregierung für die mit der Vermehrung der alliierten Truppen zusammenhängenden Fragen („Dienststelle Blank“) und wurde anschließend der erste Bundesverteidigungsminister. Zwischen 1957 und 1965 übte er das Amt des Bundesministers für Arbeit und Sozialordnung aus. Von 1965 bis 1969 nahm Blank die Position des stellvertretenden Vorsitzenden der CDU/CSU-Fraktion ein.

${ }_{94} \mathrm{Vgl}$. AdsD, Protokolle, Fraktionssitzung, 8.11.1966, S. 2.
} 
die FDP „an einer Prozedur zur Herbeiführung von Neuwahlen nicht mitwirken wolle “95. Aber für Wehner, der seine Fraktion unter allen Umständen von diesem Schritt abhalten wollte, genügte die Erklärung der Liberalen noch nicht. Er fürchtete, daß diese „Absage" von einigen Fraktionsmitgliedern als ein Signal gedeutet werden konnte. Danach sollte die SPD allein mit der Absicht vorangehen, ein konstruktives Mißtrauensvotum einzuleiten, die FDP würde dann schon folgen. Sie hatte dies gerade bei der Abstimmung über den Antrag auf die Stellung der Vertrauensfrage bewiesen. Wehners Befürchtung schien sich zu bestätigen, als der Ulmer Abgeordnete Friedrich Rau in der Sitzung am 11. November vorschlug, die Fraktion solle sich sogleich und unabhängig von den Liberalen zur Einführung eines Mißtrauensantrages entschließen. Damit war der Moment für den amtierenden Fraktionsführer gekommen, die Zügel energisch in die Hand zu nehmen und die Fraktion von der Zustimmung zu jenem Vorschlag abzubringen, den Rau gerade unterbreitet hatte. Dem Plan eines Mißtrauensvotums stellte Wehner vor den Abgeordneten seine eigene Strategie gegenüber: Man solle sich zu diesem Zeitpunkt nicht im Modell einer bestimmten Regierungskonstellation verfangen, riet er. Es bestehe kein Grund, die bisherige Entwicklung zu bedauern. Es komme eher im Gegenteil darauf an, die Krise weiter voranzutreiben. Ziel sei es, das Programm der „Liquidation einer gescheiterten Politik der Regierungskoalition" so erfolgreich wie bisher weiter durchzuführen, und Wehner brachte dieses Programm auf die Formel: „Jeder Zug jeder Seite muß von der SPD beantwortet werden." 96

Vor allem in der Öffentlichkeit solle sich die SPD als drängende und ausdauernde politische Kraft der Erneuerung erweisen. Nur über einen solchen Druck werde die Partei in die Regierung gelangen, behauptete der Fraktionschef. Im öffentlichen Bewußtsein dürfe es am Ende überhaupt gar keine andere Lösungsmöglichkeit mehr geben als eine Regierung unter Beteiligung der SPD! Wehner spekulierte darauf, daß die Verlängerung der Krise nur der Union schaden würde. Solange CDU/CSU sich weigerten, mit der SPD konstruktiv zu verhandeln, mußte sich beim Wähler der Eindruck von Unentschlossenheit, sogar von Hilflosigkeit der amtierenden Minderheitsregierung verstärken. Gleichzeitig würde das Ansehen der Opposition wachsen. Die SPD mußte lediglich darauf achten, genau den gegenteiligen Eindruck zur regierenden Partei zu erwecken. „Zug um Zug“ hieß, zunächst auf Gespräche mit allen Fraktionen zu drängen, dabei gleichzeitig deutlich zu machen, daß es den anderen Parteien an Klarheit und Entschlossenheit für die Beantwortung zukünftiger Fragen fehle. Die SPD sollte und mußte in dieser Lage die Sachthemen bestimmen. Der Anfang war schon gemacht. Das Acht-Punkte-Programm lag vor. Die SPD sei zwar nicht die größte Partei im Bundestag, aber sie könne sich als die politisch stärkste Kraft ansehen, meinte etwa auch Schmidt, da „wir die einzige politisch einige und geschlossene Partei sind, die einzige, die klare Ziele hat ${ }^{\text {"97. }}$.

Die Genossen zeigten sich beeindruckt. Die Strategie wurde einstimmig gebilligt. Mit wenigen Worten hatte Wehner die Ansätze einer sozialliberalen Zusammenarbeit in der Fraktion unterlaufen und den Vorschlag eines Mißtrauensvotums abgewehrt. Damit war Zeit gewonnen für die Vorbereitung einer Großen Koalition. Ab jetzt lief auch in der SPD-Fraktion alles auf dieses Bündnis zu.

${ }^{95}$ Die SPD-Fraktion teilt mit, 9.11.1966, S. 1; zu denjenigen, die auf ein Mißtrauensvotum hofften, zählte übrigens auch der Vorsitzende des Landesverbandes Baden-Württemberg und stellvertretende Fraktionsvorsitzende, Möller, vgl. Möller, Generaldirektor, S. 302.

${ }^{96}$ AdsD, Protokolle, Fraktionssitzung, 11.11.1966, S.2.

${ }^{97}$ Abendzeitung, München, 2.11.1966. 


\section{Das Dilemma der FDP}

Hinzu kam, daß die Liberalen es der Sache Wehners und Kiesingers einfach machten. Die Flügel paralysierten die Partei im November 1966. Auf der einen Seite standen die Anhänger der gerade zerbrochenen Regierungkonstellation mit der Union unter der Führung Mendes ${ }^{98}$. Ihnen gegenüber befanden sich die Verfechter eines Bündnisses mit der SPD, vor allem die Führer des mächtigen Landesverbandes von Nordrhein-Westfalen, Willi Weyer und Scheel. Beide Kräfte schienen gleich stark zu sein. Hätte es im November 1966 eine offene Wahl gegeben, erklärte Scheel zehn Jahre später, dann wäre das Ergebnis 50 zu 50 ausgegangen ${ }^{99}$. Die Verfechter beider Positionen neutralisierten sich. Die Liberalen waren weder handlungs- noch verhandlungsfähig. Sie seien mit zwanzig Mann in die Verhandlungen gegangen, beschrieb Barzel den desolaten Zustand: „Jeder stand gegen jeden!" 100

Das Ergebnis der Bayernwahl vom 20. November verstärkte die Apathie der FDP. Von ihrem Wahlerfolg hatten die Liberalen ursprünglich das weitere Vorgehen abhängig machen wollen. Insgesamt erzielten sie 5,1 Prozent der Stimmen. Aber nach dem bayerischen Wahlgesetz genügte allein die Überwindung der Fünf-Prozent-Hürde nicht, um in den Landtag einzuziehen. Es mußten zusätzlich noch in einem der Wahlkreise über 10 Prozent der Stimmen erzielt werden. Bisher war der FDP das immer in Franken gelungen. Aber jetzt votierten hier viele ihrer früheren Wähler für die rechtsextreme NPD. Damit mißlang der FDP die Rückkehr in das Münchner Maximilianeum.

In Bonn fühlten sich beide Parteiflügel durch die Niederlage bestätigt. Die Anhänger der alten Koalition zogen daraus den Schluß, daß die Hinwendung zur SPD ein Schritt in die falsche Richtung sei. Diese Diskussion habe der Partei geschadet. Die andere Fraktion erblickte in dem unzureichenden Ergebnis den Beweis dafür, daß man nicht weit genug auf die Sozialdemokratie zugegangen sei. Man müsse diesen Kurs jetzt weiter verfolgen. In dieser fatalen Konstellation ging die Partei in die Verhandlungsrunden mit den Kommissionen von CDU/CSU und SPD. Vor allem die Sozialdemokraten ließen sich schnell davon überzeugen, daß mit den Liberalen keine Regierung möglich sei. Die Unsicherheit der FDP-Vertreter nahm manchmal groteske Züge an. Ihre Angst, sich auf wirtschaftlichem Gebiet zu kompromittieren, führte etwa zur Weigerung, Begriffe und Wortschöpfungen des volkswirtschaftlichen Experten der SPD, Karl Schiller, zu akzeptieren wie beispielsweise „Wachstum“, „konzertierte Aktion“ oder sogar „Mitbestimmung". Schiller erklärte seinem Parteirat kopfschüttelnd, die FDP habe damit den Eindruck vermeiden wollen, sie sei jetzt „umgefallen vor den Begriffen der SPD“101. Und vor der Fraktion fügte der baden-württembergische Landesvorsitzende Alex Möller hinzu,

${ }_{98}$ Vgl. Kiesinger (Gespräch mit Baring, 16.6.1977), der später die Lage der Liberalen in der Mitte der sechziger Jahre mit viel Verständnis analysiert hat: Als Folge einer nüchternen Bilanz habe die FDP im Herbst 1966 die Koalition verlassen müssen. Denn in der Regierung mit der Union habe sie immer stärkere Verluste hinnehmen müssen. Zuletzt verlor sie 1965 achtzehn Mandate. Damit sei das Ende der Koalition Erhard/Mende voraussehbar gewesen.

${ }^{99} \mathrm{Vgl}$. Scheel, Gespräch mit Baring, 9.3.1977.

${ }^{100}$ Barzel, Gespräch mit dem Verfasser, 10.6.1988.

101 Vorstand der SPD (Hrsg.), Bestandsaufnahme, S. 76 f. Der Vorwurf, die FDP sei „umgefallen“, kam zuerst nach der Bundestagswahl 1961 auf, als die Partei erneut unter Bundeskanzler Adenauer in eine Koalition eintrat. Der FDP-Vorsitzende Mende hatte zuvor öffentlich erklärt, die FDP werde nur eine Koalition mit der Union ohne Adenauer bilden. Es kam anders. Immerhin stimmte dann Adenauer auf Druck der FDP nach der Spiegel-Krise 1962 einer Begrenzung seiner Amtszeit bis zum Herbst 1963 zu. 
es sei nicht einmal gelungen, den haushaltspolitischen Standpunkt der SPD der FDP-Expertenkommission deutlich zu machen ${ }^{102}$.

Wehner stellte vor allem die fehlende Praxis und mangelnde Erfahrung der Liberalen in der Verantwortlichkeit von Kommunen und Gemeinden heraus. Noch Jahre später meinte er, die langjährige gemeinsame Verantwortlichkeit von CDU/CSU und SPD für Kommunen und Gemeinden habe eine Übereinkunft erleichtert. Die FDP hatte „damals keine sehr glückliche Hand in bezug auf die Behandlung von gemeindepolitischen Problemen, und das schien uns bei der entstandenen Unruhe und im Industriegebiet bei den Betriebsstillegungen und so weiter das Wesentliche, die Sache mit den Gemeinden sauber in Ordnung zu bringen" ${ }^{103}$.

Selbst die Berliner Sozialdemokraten, die seit 1963 mit der FDP gemeinsam den Senat stellten, verloren bald ihr Interesse, in Bonn die Grundlage eines sozialliberalen Bündnisses zu schaffen. Dabei spielten auch persönliche Antipathien eine Rolle. Brandt wollte am Ende nicht länger auf die Bedenken des ehemaligen Finanzministers Heinz Starke eingehen. Starke sei ein komplizierter Mann, der an sich selbst leide, hieß es später in der FDP. Er sei ein Mann immer neuer Ideen und damit auch immer neuer Zweifel. Der Finanzexperte, so seufzte Mende einmal, habe alles genau wissen, alles schriftlich haben wollen. Nachdem die Sachthemen mit der SPD bereits festgelegt waren, brachte er noch einmal die Sozialpolitik auf, deren Konzeption er nicht verstanden zu haben glaubte oder kritisierte.

Ein Problem für die Liberalen stellte auch die Person Brandts dar. Einige Abgeordnete sperrten sich gegen einen Kanzler Brandt. Das galt im besonderen für den Bayern Josef Ertl und den hessischen Abgeordneten W. Alexander Menne. Beide seien „ums Verrecken nicht" für eine Kanzlerschaft Brandts zu gewinnen gewesen, berichtet Mende ${ }^{104}$. Aber man habe im Bundestag jede Stimme benötigt, bei einer so knappen rechnerischen Mehrheit von insgesamt sechs Stimmen. Menne habe sich dann an den hessischen Ministerpräsidenten Georg August Zinn und an Carlo Schmid mit der Bitte gewandt, sich anstelle Brandts für das Kanzleramt zu bewerben. Aber beide hätten abgelehnt. Brandt wiederum bekannte, am Ende habe er es seinerseits mit den Liberalen satt gehabt ${ }^{105}$.

Bei der CDU/CSU war das ganz anders. Die Gespräche zwischen den großen Parteien verliefen intensiver und führten zu genaueren Resultaten. Der SPD-Pressedienst betonte, daß im Vergleich zu den Verhandlungen mit den Liberalen die „Konkretisierung der zu ergreifenden Maßnahmen [...] nicht zuletzt zur Entwicklung einer konstruktiven Deutschland- und Außenpolitik“ mit der CDU/CSU „detaillierter und in der Substanz eindeutiger" gewesen sei ${ }^{106}$. In der Außenpolitik hatte es überraschend wenig Unstimmigkeiten gegeben. Der SPD-Vorsitzende gestand am 28. November 1966 vor dem Parteirat, er sei erstaunt darüber, „in wie umfassendem Maße der Prozeß, der bei der CDU im Gange ist, dazu führte, daß die, mit denen wir zu tun haben, den wesentlichen Teil der Punkte 1 bis 4 unserer 8 Punkte [...] zur Grundlage der künftigen Politik“ gemacht hätten - „,was die Deutschlandpolitik angeht mit einer einzigen Ergänzung, die den Sinn nicht ändert, sondern lediglich noch etwas deutlicher macht, daß dort, wo wir von völkerrechtlicher Nichtanerkennung sprechen, im Ausland nicht der Eindruck

\footnotetext{
102 Vgl. Möller, Generaldirektor, S. 307: „Als Vorsitzender und persönlich war ich an einem positiven Ergebnis stark interessiert. Es ist nicht gelungen, Vernünftiges zu erreichen.“

${ }_{103}$ Terjung (Hrsg.), Der Onkel, Wehner in der ARD am 5.1.1980, S. 158.

${ }_{104}$ Mende, Gespräch mit Baring, 30.3.1977.

$105 \mathrm{Vgl}$. Brandt, Begegnungen, S. 174.

106 SPD-Pressedienst, 28.11.1966, S. 1a.
} 


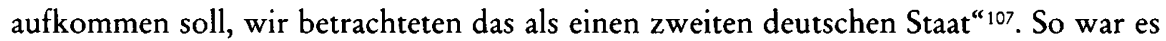
nicht verwunderlich, daß die anderen SPD-Verhandlungsführer Möller, Schiller, Schmidt und am Ende auch Brandt mit Wehner zu dem Schluß kamen, ihrer Fraktion ein Regierungsbündnis mit der Union vorzuschlagen.

\section{Der ehemalige Kommunist und der ehemalige Pg}

Die politische Entwicklung begünstigte das von Kiesinger und Wehner angestrebte Bündnis. Zwar mußte der SPD-Politiker seine Fraktion an der Klippe des Mißtrauensvotums vorbeiführen, was ihm mit Raffinesse gelang. Aber die Übereinstimmung in der Sache zwischen den Verhandlungskommissionen von SPD und CDU/CSU ließ in der sozialdemokratischen Führungsgruppe keinen Zweifel darüber aufkommen, für welchen Regierungspartner man sich entscheiden würde. Damit hatte sich die Vereinbarung zwischen Kiesinger und Wehner als realistisch erwiesen. Aus der privaten und persönlichen Übereinstimmung in den Gesprächen entstand zwischen den beiden bald eine Partnerschaft. Der Schwabe und der Sachse fanden sich künftig nicht nur in Krisenzeiten zusammen, um die Optionen der Regierung durchzusprechen und den gemeinsamen Kurs zu verabreden. Besonders im ersten Jahr der Koalition kamen beide häufig im Palais Schaumburg, später im Bungalow zusammen. Der Wille, die Koalition unter allen Umständen weiterzuführen, prägte diese Gemeinschaft. Wenn die Parteien nicht mehr miteinander verhandeln konnten, dann blieb nur noch dieses Gespann übrig, um einen Ausweg aus einer verfahrenen Situation zu finden. Manche der Treffen dauerten bis weit nach Mitternacht. Was neben der Tagespolitik besprochen wurde, wie persönlich die Themen waren, kann man nur erahnen. Die engen Berater des Kanzlers, wie der Persönliche Referent Hans Neusel oder der Staatssekretär im Presseamt Diehl, die Wehner im Kanzleramt erlebten, zeigten sich von seiner privaten, oft humorvollen Seite überrascht. Sie hatten den SPD-Parlamentarier im Bundestag anders erlebt: ruppig, aufbrausend, mit verbissener Miene zuhörend, dann wieder ganz in sich versunken, scheinbar abwesend und plötzlich wieder da - einem vulkanischen Ausbruch gleich, eruptiv. Im privaten Gespräch konnte er dagegen unterhaltend sein, gelöst, sogar heiter wirken. Wehner besaß daneben die Eigenschaft, den langen Monologen, die Kiesinger liebte, geduldig zuzuhören.

Der aus der Kleinstadt Ebingen stammende Schwabe war fasziniert von dem Dresdner. Der Christdemokrat hielt den Sozialdemokraten schon 1964 für den „bedeutendsten Politiker" in der Bundesrepublik nach Adenauer ${ }^{108}$. Für Kiesinger war Wehner zwar ein Utopist, der aber dennoch den Kontakt zur Realität nicht verloren hatte. Wehner wisse genau, daß er für sein Programm die parlamentarische Mehrheit brauche, meinte er. Deshalb sah er in Wehner auch keinen verkappten Kommunisten. In einem Gespräch erklärte Kiesinger 1978: „Ich habe ihn nie für einen Krypto-Kommunisten gehalten. “ 109 Der Kanzler hat daher seinen Minister häufig vor Verleumdungen in Schutz genommen, gerade auch vor Angriffen der konservativen Presse. So beschwerte er sich etwa beim Leiter des Katholischen Büros im Kommissariat der Deutschen Bischöfe, dem Weihbischof Heinrich Tenhumberg, als die Neue Bildpost im April 1967 in Wehner das „Trojanische Pferd der Kommunisten in der Regierung" sehen wollte ${ }^{110}$. Schriftlich bedau-

107 Vorstand der SPD (Hrsg.), Bestandsaufnahme, S. 57.

108 Majer, Gespräch mit dem Verfasser, 16.12.1988.

${ }^{109}$ AdKASt, Kiesinger I - 226, F/3. A 322, Gespräch mit Löwe, 31.1.1978, S. 43.

110 Neue Bildpost, 30.4.1967. 
erte er gegenüber Wehner die Veröffentlichung. Der Katholik erklärte, er habe mit Entrüstung den Artikel gelesen, in dem Wehner in "unglaublicher Weise" angegriffen werde. Daß die Neue Bildpost in und vor katholischen Kirchen zum Verkauf feilgeboten werde, mache für ihn die Sache noch gravierender. Er könne hierin nur „den Versuch Unbelehrbarer sehen, den Geist der Zusammenarbeit in der Großen Koalition zu zerstören" ${ }^{111}$. Dankbar nahm Wehner diese Erklärung zur Kenntnis.

Für Wehner, so sah es Kiesinger, standen 1966 nicht so sehr die Inhalte im Vordergrund, sondern der Wunsch, die SPD an die Macht und in die Regierung zu bringen: „Das war das für ihn wirklich Wichtige." 112 Kiesinger ortete hier zugleich die Schwäche des Sozialdemokraten. Denn Wehners Drang in die Regierung habe ihn dazu geführt, "alle möglichen" Konzessionen zu machen. Er habe gewußt, was Wehner wollte, wie er sich die Dinge dachte, betonte Kiesinger immer wieder. Sein Gesamteindruck über den anderen Gründungsvater der Großen Koalition blieb daher auch im Rückblick positiv. "Ich habe mich über Wehner in keiner Weise zu beklagen“", faßte er 1978 zusammen ${ }^{113}$.

$\mathrm{Da}$ das Verhältnis der beiden auch von gegenseitiger Bewunderung für die jeweils andere Persönlichkeit und Stellung geprägt war, ist schon angeklungen. Kiesinger zeigte sich etwa von der scheinbar schier unerschöpflichen Energie des SPD-Politikers beeindruckt. Von Wehner hieß es, und Kiesinger stellte dies nicht in Frage, er stehe um fünf Uhr auf und beantworte Briefe aus seinem Wahlkreis oder woandersher auf seiner kleinen Reiseschreibmaschine „Erika“. Kiesinger war da anders, ein Spätaufsteher. In seiner Zeit als Ministerpräsident pflegte er erst gegen elf Uhr in der Villa Reitzenstein einzutreffen. Auch den Abend ließ er sich nicht gerne durch Geschäfte verderben. In Stuttgart konnte er sich das erlauben, als Kanzler durfte er es sich - zu seinem Bedauern nicht mehr leisten, wann er wollte Konzerte, Oper oder Schauspiel zu besuchen.

Dem Kanzler gefielen auch die Umgangsformen des Politikers. Wehner, im Jahre 1906, nur zwei Jahre nach Kiesinger, geboren, hatte offensichtlich Sinn für bürgerliche Höflichkeit. Die sozialdemokratische Abgeordnete Marie Schlei beschrieb einmal, wie Wehner auf einem Fraktionsfest einer Sängerin Rosen überreicht und ihr mit einer sehr galanten Verbeugung die Hand geküßt habe, „wie das Polen oder Wiener so gut können “ ${ }^{114}$.

Auf korrekte, manchmal überkorrekte Weise bemühte sich Wehner um Kiesinger. Er sprach ihn, wie bereits erwähnt, schon mit „Herr Bundeskanzler" an, als man noch um die Koalition verhandelte. Auch im privaten Gespräch blieb es bei der höflichen Formm ${ }^{115}$. $\mathrm{Da}$ Wehner spürte, wie empfänglich der Kanzler für Schmeicheleien war, behandelte er Kiesinger auch mit einer gewissen Unterwürfigkeit, der „vermeintlichen Demut", wie Günter Grass das genannt hat. Aber Unterwürfigkeit und Forderungen fielen bei ihm immer zusammen. Er wirkte dann so, als ob er sagen wollte: Ich muß das fordern, aber das hat mit meiner Person nichts zu tun, und, bitte, mache mich nicht dafür verantwortlich. Wenn Kiesinger seinen Vorschlägen etwa in der Deutschlandpolitik folgte, wie das im Jahr 1967 oft der Fall war, dann lobte er den Kanzler. Er stellte seine eigene Leistung dabei zurück, betonte die geschichtliche Dimension, in die eine Entscheidung des Kanz-

I" AdKASt, Kiesinger I - 226, D/IV.6, Kiesinger an Wehner vom 27.4.1967. Tenhumberg entschuldigte sich persönlich bei Wehner. Tatsächlich unterblieben künftig in dieser Zeitung entstellende oder diffamierende Berichte über ihn.

112 AdKASt, Kiesinger I - 226, F/3., A 322, Gespräch mit Löwe, 31.1.1978, S. 43.

113 Ebenda.

114 Jahn (Hrsg.), Wehner, Schlei im Gespräch mit Dettmar Cramer, S. 256.

115 Vgl. Diehl, Gespräch mit dem Verfasser, 29.11.1989. Übrigens duzten sich auch die anderen sozialdemokratischen Minister am Kabinettstisch nie. „Das kam nur vor nach Beendigung der Sitzung, im Gespräch, beim Hinausgehen." 
lers gestellt werden müsse. Für Wehner zählte der Bundeskanzler zur Kategorie der „vernünftigen ", Menschen, also zur höchsten der von ihm erstellten drei Kategorien ${ }^{116}$. Wehner respektierte Kiesinger und schätzte ihn auch menschlich. Kiesinger sei eine „ehrliche Haut" vertraute er seinem Mitarbeiter Hermann Kreutzer an. Schade war nur, daß der Schwabe als Repräsentant des Bürgertums für den ehemaligen Kommunisten soziologisch zu einer politisch vorübergehenden Erscheinung gehörte ${ }^{117}$.

Diese Bemerkung Wehners verweist auf einen Widerspruch. Er bewunderte Kiesinger als Vertreter des althergebrachten Bildungsbürgertums. Wehner selbst war - den Vorstellungen der sozialistischen Tradition entgegen - dem Bürgerlichen sehr verhaftet. Bürgerlich erschien vor allem die private Umgebung des Politikers seinen Beratern. Kreutzer erinnert sich an einen Sonntagsbesuch im Winter 1970 am Heiderhof. Da habe Wehner im Ledersofa gesessen, eingepaßt, Lotte gemütlich neben Wehner. „Er mit seinen Filzpantoffeln, gelb karierten, wie man sie von Thüringen her kennt, und man hatte nicht den Eindruck, daß es sich hier um einen der mächtigsten Männer handelt." Für Wehner schien es vor diesem Hintergrund etwas Besonderes zu sein, mit dem christdemokratischen Politiker zusammenzuarbeiten. „Man konnte mit ihm [Kiesinger] über alles ernsthaft reden, er mit mir, und ich mit ihm. Das Verhältnis hatte ich vorher nie gehabt mit einem Mann in entsprechender Stellung, noch nachher. " 118 Kiesinger in seinem Amt schien für Wehner etwas Unnahbares zu haben. Der Respekt vor dem hohen Amt ließ für den Schuhmachersohn noch nach vielen Jahren das Verhältnis zu Kiesinger in einem besonderen Licht erstrahlen. Aber es waren auch persönliche Fähigkeiten Kiesingers, die Wehner bewunderte. Dem Schwaben schien einfach alles von selbst zuzufliegen. Kiesinger strahlte eine Sicherheit und ein Zutrauen in den guten Fortgang seines Schicksals aus, das seine Umgebung verblüffte. Daß diese Sicherheit in seiner schwäbischen Heimat wurzelte, sahen seine Berater deutlich. Es habe ihn immer wieder, gerade auch in der Zeit der Kanzlerschaft, von Bonn nach Tübingen gezogen, schreibt Diehl. Er habe sich dort „irgendwie sicherer" gefühlt, "gestärkt im gewohnten Umfeld seiner Heimat ${ }^{" 119}$. Selbst die harte Kindheit im schwäbischen Ebingen, wo er 1904 geboren worden war, die kargen Verhältnisse, die Armut, den frühen Verlust seiner Mutter, hat Kiesinger im Rückblick als ein stilles Glück beschrieben - in liebevollen, anrührenden und bewegenden Worten, die die bittere Wahrheit in den Hintergrund drängen ${ }^{120}$. Die Scbwäbische Kindheit ist daher ein offenes Buch, weil es die Stärke Kiesingers zeigt, das Schöne zu beschreiben und in Erinnerung zu behalten, die üblen Erfahrungen aber ins Vergessen zu drängen. Mit Stolz hat er immer wieder seine Streiche der Jugendzeit erzählt. Ganz anders als Wehner, der seiner in Dresden gebliebenen Kusine später sogar ausdrücklich verbot, über seine Jugendstreiche zu berichten. Kiesinger hat sich Mühe gegeben, die Bedeutung seiner schwäbischen Heimat als Quelle seiner Lebenskraft zu schildern. Es war eine Erdverbundenheit, die ihm offensichtlich aus dem kargen Boden der schwäbischen Alb unerwartete und ungeahnte Kraft zu geben schien. Auch dies hatte Kiesinger Wehner voraus. Für Wehner selbst war zwar Dresden als Heimat wichtig. Aber sie blieb ihm, der früh hatte ins Exil gehen müssen, entfernt. Schon in seiner Kindheit mußte Wehner mit seinen Eltern oft umziehen, zunächst innerhalb Dresdens, bald aus der Residenz-

116 Kreutzer, Gespräch mit dem Verfasser, 22.8.1988. Die zweite Kategorie bezeichnete er als die "Arschlöcher“, dann kamen die „Verlorenen“.

117 Vgl. ebenda.

${ }^{118}$ Schmoeckel/Kaiser, Vergessene Regierung, Kiesinger im Gespräch mit Kaiser, 1983, S. 65.

${ }_{119}$ Diehl, Kiesinger, S. 202.

${ }^{120}$ Vgl. Kiesinger, Schwäbische Kindheit. 
stadt in einen Vorort. Dies habe bei ihm Spuren hinterlassen, meint sein Biograph, „vor allem als Gefühl dauernder Nichtzugehörigkeit, gesteigerter Lebensunsicherheit " ${ }^{121}$. So konnte sich eine enge Verbundenheit, wie sie bei Kiesinger so deutlich wurde, bei ihm nicht entwickeln.

Daß Dresden für Wehner dennoch ein wichtiger Bezugspunkt gewesen ist, zeigen seine Gesten, etwa wenn er Dresdner Stollen an Freunde verschickte oder auch verschiedene heimische Küchenrezepte beherrschte. Aber letztlich blieb ihm die Vaterstadt nicht nur geographisch fern. Kiesinger dagegen zelebrierte seine Heimat- und auch Naturverbundenheit, die Wehner ihm neidete. Als der Kanzler auf einem Spaziergang mit den Spitzen der Koalitionsparteien in Kreßbronn am Bodensee nebenbei ein vierblättriges Kleeblatt fand, kommentierte Wehner tief beeindruckt: „Dem gelingt auch alles!“

\section{Kiesingers Weg}

Ein wesentlicher Unterschied zwischen Kiesinger und Wehner bestand in der Distanz zur Politik, die Kiesinger auszeichnete. Wehner war von Jugend an ein politisch denkender und auch handelnder Mensch; Kiesinger bewahrte sich eine Unabhängigkeit von der Politik, einen spielerischen Umgang, was wiederum auf Wehner provozierend wirkte: Kiesinger war auf die Politik nie angewiesen. Wenn er wollte, vernachlässigte er sie, kümmerte sich um die schönen Seiten des Lebens, las, genoß. Diese innere Souveränität erklärt sich aus seiner Biographie.

Kiesinger wuchs auf als ältester Sohn eines kaufmännischen Angestellten in der evangelisch geprägten, nur wenige Seelen zählenden Gemeinde Ebingen im Altwürttembergischen. Seine Mutter starb nur ein halbes Jahr nach seiner Geburt. Aber nach eigener Aussage ist ihm dieser Verlust erst als Neunjährigem bewußt geworden, und er selbst ist schnell darüber hinweggekommen ${ }^{122}$. Dafür ist ihm die konfessionelle Herkunft bedeutsam erschienen. Anders als Wehner, der über die Religiosität seiner Eltern wenig gesagt hat - so selbstverständlich erschien ihm der lutherische Hintergrund, vor dem er aufwuchs -, fehlt bei Kiesinger in dessen Kindheitsbeschreibungen nie der religiöse Rahmen. Dieser war auch nicht unkompliziert. Sein Vater zählte zur evangelischen, seine Mutter, auch seine Stiefmutter zur katholischen Konfession - beide gingen eine der ersten zwischenkonfessionellen Ehen ein. Auf Drängen der katholischen Kirche wurde auch Kurt selbst katholisch getauft, und zwar auf den Namen Konrad. Noch eindrucksvoller aber erschien dem Jungen die pietistische Atmosphäre, die ihn als Kind überall begleitete und eine mystische und phantastische Stimmung hervorrief, an die er sich sein Leben lang erinnerte. So blieb die Erinnerung an die Furcht beim Erscheinen des Halleyschen Kometen im Jahre 1910 und insbesondere vor künftigem Unheil beim Erdbeben im folgenden Jahr auch im Alter wach. Unter klarem Sternenhimmel hätten die aus den Häusern geeilten Menschen die ganze Nacht lang fromme Choräle gesungen. „Ich erwartete den Untergang der Welt und blickte suchend zu den Sternen auf, wo bald das flammende Zeichen des Kreuzes erscheinen mußte. “ ${ }^{123}$

Kiesinger lernte bald, sein Leben als unter einem besonderen Stern stehend zu begreifen. Und wirklich: Was er sich vornahm, meist gelang es ihm. 1922 war beispielsweise durch die schnell wachsende Geldentwertung der weitere Besuch des katholischen Lehrerse-

\footnotetext{
121 Soell, Wehner, S. 93.

122 Vgl. Kiesinger, Jahre, S. 24.

${ }^{123}$ Ebenda, S. 26.
} 
minars in Rottweil und damit der notwendige Abschluß des damals Achtzehnjährigen in Frage gestellt. Kiesinger verfiel auf den naheliegenden Gedanken, sich das notwendige Geld als Werkstudent zu verdienen. Aber die kurze Ferienzeit von wenigen Wochen hätte ihm nicht erlaubt, genug Geld zusammenzutragen. Daher machte er beim „Kultministerium " - so wurde es damals in Württemberg genannt - eine Eingabe und bat um eine Verlängerung seiner Ferienzeit. Tatsächlich gewährte ihm die Landesregierung die Verlängerung. Sein Antrag war eine unerhörte, dreiste Sache - und wurde etwa bei seinen Lehrern auch als solche verstanden. Immerhin wandte er sich an die höchste Stelle im Lande. Wahrscheinlich war derartiges kaum jemals vorgekommen.

Der Erfolg bestärkte Kiesinger in dem Glauben, er könne auf ungewöhnlichem Wege alles erreichen. Wie selbstverständlich ist ihm später beispielsweise der Gedanke gewesen, eines Tages Bundeskanzler zu werden. Vieles schien ihm scheinbar ohne eigenes $\mathrm{Zu}$ tun zu gelingen. Bei einem seiner Ferienjobs entdeckte der Industrielle Friedrich Haux den Lernwilligen, der sich fortan finanziell um den Schützling kümmerte. Kiesinger begann sein Studium und konnte es sich leisten, von der Universität Tübingen nach Berlin zu wechseln. Das trug weiter zum unerschütterlichen Vertrauen in das eigene Schicksal bei. In einem Gespräch erklärte Kiesinger 1981, er habe immer das Gefühl gehabt, daß ihm „nie etwas passieren" könne. Haux kam 1928 bei einem Flugzeugabsturz ums Leben; Kiesinger war eingeladen worden, an diesem Flug teilzunehmen, er aber hatte abgelehnt. In seinen Memoiren heißt es, er habe nie das Vertrauen verloren, daß „mein Leben letztlich von einer gütigen Macht gelenkt werde" ${ }^{124}$.

Kiesinger hat seinen Lebensweg als vorbestimmt begriffen. So glaubte er, daß die Zahl "6" eine besondere Bedeutung für sein Leben besitze. Am 6. April war er geboren, sechs Monate später seine Mutter gestorben. Ab dem Jahr 1928 habe sich sein Leben im SechsJahre-Rhythmus abgespielt - von kleinen Lücken abgesehen. Damals verunglückte der Mentor Haux tödlich. 1934 legte Kiesinger in Berlin sein Assessorexamen ab; 1940 wurde er im Auswärtigen Amt dienstverpflichtet, und sein erster Sohn wurde geboren; 1946 entließ man ihn aus dem Internierungslager, 1958 übernahm er das Amt des Ministerpräsidenten von Baden-Württemberg; 1964 erlebte er den großen Wahlsieg in diesem Bundesland, 1976 hatte er einen schweren Autounfall 125.

Wehner hat dieses tiefe Zutrauen Kiesingers in das Leben gespürt und bewundert. Sein Leben war anders verlaufen und vom Kampf um politische Ideale und deren Verwirklichung bestimmt worden. Dieser Kampf führte den jungen Wehner zunächst 1923 zur Sozialdemokratie, dann 1927 zur KPD, und schließlich zwang er ihn ins Exil. Die Auseinandersetzung zwischen dem Nationalsozialismus und der Sowjetunion brachte den Kommunisten Wehner und das NSDAP-Mitglied Kiesinger in unangenehme und bedrohliche Situationen. Während Kiesinger, der unpolitische Mitläufer, zunächst in Berlin als erfolgreicher Repetitor arbeitete, hatte Wehner auch hier das schwerere Los getroffen. In Moskau entkam er nur knapp der willkürlichen Mordmaschinerie des stalinistischen Systems, überlebte aber um den hohen Preis des Verrats ${ }^{126}$; Kiesinger entging dem drohenden Kriegseinsatz durch eine Dienstverpflichtung des Auswärtigen Amtes.

\footnotetext{
${ }^{124}$ Ebenda, S. $57 \mathrm{f}$.

${ }^{125}$ Vgl. Kiesinger, Gespräch mit Baring, 12.5.1982.

126 Vgl. BStU, ZA, SdM 1856, Bl. 1-243, insbesondere die Akten, die das MfS vorwiegend über Wehner als Funktionär der KPD im Zeitraum 1937-1942 zusammenstellte. Siehe dazu auch Reuth, Gefährlich, den Verräter in einer Art zu analysieren, die dazu führen wird, daß man ihn versteht. Herbert Wehners Verstrickungen in Moskau. Dokumente der Denunziation, in: Frankfurter Allgemeine Zeitung, 10.1.1994.
} 
Sie rückte ihn aber derart in die Nähe des Naziregimes, daß er sich später gegen Vorhaltungen nicht entscheidend zur Wehr setzen konnte. Beide, Kiesinger und Wehner, haben sich wegen ihrer Rolle wiederholt rechtfertigen müssen. Wehner schwor zwar dem Kommunismus ab, aber er wußte, daß man ihm „die Haut in Streifen abziehen“ werde, wie er dem SPD-Parteivorsitzenden Kurt Schumacher erklärte, als er 1949 für den Bundestag kandidieren sollte ${ }^{127}$.

So kamen Wehner und Kiesinger, die beide 1949 in den Bundestag einzogen, aus ganz unterschiedlichen Richtungen. Schnell übernahmen beide wichtige Aufgaben und Funktionen. Kiesinger wurde sofort in den Fraktionsvorstand der CDU gewählt - ein unerwarteter Aufstieg des nur wenige Monate zuvor in die Politik eingetretenen Juristen. Im Bundestag bewies er sein Talent für die Rechtspolitik wie für die auswärtigen Angelegenheiten. Als außergewöhnlich gewandter Rhetor machte sich Kiesinger dann auch bald einen Namen. Er galt als wichtigster außenpolitischer Sprecher der Christdemokraten, und man räumte ihm hervorragende Chancen auf ein Ministeramt ein. Auch Wehner gelang ein erstaunlicher Einstieg. Er wurde auf Anhieb zum Vorsitzenden des Ausschusses für gesamtdeutsche und Berliner Fragen gewählt.

Beide Politiker lernten sich in ihren neuen Funktionen kennen und respektieren. Kiesinger erwähnt in seinen Erinnerungen ausdrücklich, daß Opposition und Regierungsparteien schon damals weitgehend in deutschlandpolitischen Fragen übereingestimmt hätten. Wehner habe für die SPD beispielsweise im September 1951 den Plan der Bundesregierung für freie gesamtdeutsche Wahlen begrüßt. Er, Kiesinger, habe daraufhin erreichen können, daß der gesamte Bundestag mit Ausnahme der Kommunisten „nicht nur der Regierungserklärung, sondern auch einem Antrag der SPD zu freien Wahlen in ganz Berlin" zugestimmt habe ${ }^{128}$. Es war also etwas daran, wenn es später hieß, Kiesinger habe sich häufig, manchmal auf Kosten von CDU-Positionen, mit der SPD geeinigt. Die Große Koalition antizipierte er bereits als Abgeordneter im Bundestag.

\section{Webners Geschick im Umgang mit Kiesinger}

Im Verhältnis zwischen Kiesinger und Wehner gab es von Beginn an ein gewisses Ungleichgewicht. Wehner schien den persönlichen Umgang dazu zu nutzen, den Kanzler von seiner Deutschlandpolitik überzeugen zu wollen. Dies schien um so leichter zu sein, als Kiesinger ein wenig um Wehner warb. Er war stolz darauf, daß ihm der SPD-Politiker das häufig zitierte Telegramm, „Bonn wird ärmer. Wehner“, 1958 nach Stuttgart hinterher geschickt hatte. Kiesinger glaubte, darin habe sich die persönliche Verbundenheit Wehners gezeigt. Aber das täuschte. Wehner schrieb viel, gerade auch Widmungen in Bücher, die Kiesinger regelmäßig während und nach dem Ende der Koalition erhielt und auf die er mit besonderem Stolz hinwies. Allerdings, was Kiesinger nicht wußte, sie waren gleichlautend an fünfzig andere Adressaten gegangen ${ }^{129}$.

Kiesinger ließ sich in seiner Politik jedoch nicht allein vom persönlichen Verhältnis beeindrucken. In den Gesprächen über die Deutschlandpolitik gab er sich von Beginn

${ }^{127}$ Scholz, Wehner, S. 75.

${ }_{128}$ Kiesinger, Jahre, S. 422.

${ }^{129}$ Vgl. Majer, Gespräch mit dem Verfasser, 16.12.1988. Majer erinnert sich, daß Kiesinger ihn am 24.12.1966 "sichtlich bewegt“ auf die Widmung Wehners in den gerade erschienenen Gesprächen Wehners mit Gaus aufmerksam gemacht habe: „Mit Respekt und Zuneigung“ lautete der Text. Gaus habe Majer dann später erzählt, daß ihm Wehner die gleiche Widmung in sein Exemplar geschrieben habe. 
an aufgeschlossener als die meisten CDU-Politiker. Wehner und die anderen Sozialdemokraten bekamen den Eindruck, als ob sich ihre Politik der Annäherung und Umarmung Ost-Berlins mit den Absichten des Kanzlers durchaus vereinbaren ließ. Aber das erwies sich später als falscher Eindruck. Kiesinger lag vor allem das Verhältnis zu Moskau am Herzen. Solange die Deutschlandpolitik dem Ziel der Annäherung an die Sowjetunion diente, konnte er unbesorgt die Initiativen Wehners begrüßen und unterstützen. Sobald aber diese Politik an ihr Ende gelangt war, blockierte Kiesinger jede weitere Bemühung. Aber Kiesinger verschwieg diesen Vorbehalt, solange er konnte. Daher machte er zunächst dem Koalitionspartner gegenüber den Druck der eigenen Partei für seine Zurückhaltung geltend oder verschanzte sich, ab August 1968, hinter den allgemein skeptischen Haltungen im Westen nach dem Einmarsch der Sowjets in die ČSSR. Auf jeden Fall schenkte er Wehner erst dann reinen Wein ein, als es sich nicht mehr vermeiden ließ - im Frühjahr 1969.

Vielleicht war es klug, Wehner jahrelang im Glauben zu lassen, daß er uneingeschränkt dessen Politik unterstütze. Vielleicht lag gerade darin das Geheimnis seiner Fähigkeit zur Führung eines Regierungsbündnisses starker Persönlichkeiten. Dennoch mußte diese Haltung auf lange Sicht zum Bruch des Bündnisses führen. Das Verhältnis der Gründungsväter stand also von Beginn an auf einem schmalen Fundament: Wehner ging es vor allem um seine deutschlandpolitischen Ziele; Kiesinger tat am Anfang so, als ob er diese Politik billige und unterstütze, obwohl er in Wahrheit etwas anderes anstrebte. Sobald sich die teilweise widersprüchlichen Interessen nicht mehr deckten, würde auch der Zusammenhalt wegfallen. Aber zunächst hielt das Bündnis eng zusammen, und die Belastbarkeit wurde schon in den ersten Wochen vor der Regierungsbildung auf eine harte Probe gestellt.

\section{Die Rolle Hecks am Ende der Koalitionsverhandlungen}

Drei Tage vor der endgültigen Entscheidung in den Fraktionen wäre das Unternehmen beinahe noch gescheitert. Die Gefahr kam, was Kiesinger nicht hatte vorausahnen können, aus seiner unmittelbaren Umgebung. Der CDU-Generalsekretär Heck, der auch an den ersten Gesprächen zwischen Wehner und Kiesinger teilgenommen hatte, frühstückte am Mittwoch, dem 23. November 1966, in der Wohnung Wehners. Beide besprachen die Entwicklung in Nordrhein-Westfalen, die sich in den Tagen zuvor zugespitzt hatte. Dort war seit der Juliwahl keine Ruhe eingekehrt. Zwar bestand die CDU/FDP-Koalition formal weiter mit der Mehrheit von einem Mandat. Aber die SPD lebte mit der $\mathrm{Zu}$ versicht des Siegers. Als stärkste Fraktion konnte sie sich Zeit lassen und abwarten, bis die Koalition in Düsseldorf zerbröckelte. Gleichzeitig mit der Entwicklung zur Großen Koalition in Bonn verdichteten sich Gerüchte, wonach eine sozialliberale Koalition in Nordrhein-Westfalen unmittelbar bevorstand. Ohne sich vorher mit Kiesinger abgesprochen zu haben ${ }^{130}$, erklärte nun Heck Wehner, wenn die Entwicklung in Düsseldorf nicht aufgehalten werde, seien alle bisherigen Bemühungen auf Bundesebene um ein Bündnis der beiden Parteien gegenstandslos. Auch in Düsseldorf müsse eine Große Koalition gebildet werden. Falls die SPD dort die Gegenkoalition abschließen wolle, sei alles hier zwischen ihnen hinfällig! ${ }^{131}$

${ }^{130}$ Vgl. Meyers, Gespräch mit dem Verfasser, 25.10.1989. Die CDU hatte ihren Ministerpräsidenten nicht instruiert, wie er sich in dieser Lage verhalten solle.

131 Vgl. Heck, Gespräch mit dem Verfasser, 4.10.1988; siehe auch Heck, Gespräch mit Dreher, 6.12.1983, S. 2. 
Wie kam Heck dazu, in eigenmächtiger Weise zu handeln? Zunächst empfand es der Generalsekretär als selbstverständlich, für Kiesinger die harten Verhandlungen im Hintergrund zu führen. Heck kannte die Schwächen und Stärken seines Landsmannes gut. Zum 60. Geburtstag hatte er über Kiesinger geschrieben, der Mensch und Politiker sei zum Intrigieren unfähig. Kiesinger liebe das Spiel hinter den Kulissen nicht. Der politische Rhetor vertraue vielleicht zu sehr der Macht seiner Argumente ${ }^{132}$. Er selbst war da anders. Als Persönlichkeit wirkte er bescheiden, beinahe unscheinbar. Aber er war ein unermüdlicher Organisator, der die Interessen seiner Partei über alles stellte und sie hartnäckig zu vertreten wußte. Heck kannte die Partei seit Beginn der fünfziger Jahre. Als ihr erster Bundesgeschäftsführer hatte er die CDU mit und unter Adenauer zum Erfolg geführt. Die berühmten Plakate „Alle Wege des Marxismus führen nach Moskau“ (1953) und „Keine Experimente“ (1957) entstanden in Hecks Wahlkampfkontor. In der Partei selbst festigte sich seine Stellung mit dem Gewinn der Bundestagswahl von 1953 und besonders mit der 1957 erzielten absoluten Mehrheit. Von den Medien beinahe unbeachtet, wuchs Heck langsam zu einem geachteten Führer der CDU heran. Seit 1957 war er Mitglied des Bundestages, ab 1961 für ein Jahr Parlamentarischer Geschäftsführer der CDU/CSU-Fraktion, anschließend Bundesminister für Familie und Jugend. 1966 wurde er zum Generalsekretär der CDU gewählt.

Erstmals trat Heck im Herbst 1966 auch öffentlich hervor. Am 6. November kommentierte er das schlechte Abschneiden seiner Partei bei den Landtagswahlen in Hessen vor den Fernsehkameras. Die CDU war von 28,8 auf 26,4 Prozent der Stimmen abgerutscht. Im Präsidium wollte sich niemand bereit erklären, zu diesem Ergebnis Stellung zu nehmen. Alles war erleichtert, als jemand meinte, das sei doch die Pflicht des Generalsekretärs. Heck trat vor die Kameras und schlug sich leidlich, wie er später selbst fand ${ }^{133}$. Vierzehn Tage später gab er an gleicher Stelle zur Bayernwahl seinen Kommentar ab. Jetzt hatte sich die Situation umgekehrt. Die CSU konnte nicht nur ihr vormalig erreichtes Ergebnis halten, sondern sogar verbessern. Vier Jahre zuvor hatte sie 47,5 Prozent erhalten, jetzt waren es 48,1. Die SPD gewann zwar auch einen halben Prozentpunkt dazu, erhielt aber insgesamt nur 35,8 Prozent der Stimmen. Im Fernsehen erklärte Heck: „Ich sehe darin erstens eine Bestätigung dafür, daß eben wirklich in Bayern recht solid regiert worden ist, und auch dafür, daß in Bonn die CDU/CSU wieder Tritt gefaßt hat. “ ${ }^{134}$ Das war „aufmunternd“ für die eigenen Leute gemeint, sagte Heck hinterher. Aber jene Äußerung weckte das Mißtrauen Wehners. An diesem Abend wollte sich der amtierende SPDFraktionsvorsitzende über den Ausdruck „Tritt gefaßt“ nicht beruhigen. Drohend und grimmig sagte er im Fernsehen kurz vor Mitternacht zu Heck: „Wenn Sie dabei bleiben, dann gibt es hier keine Lösung, dann müssen Sie mit Ihrer Minderheitsregierung den Tritt, den Sie geglaubt haben, gefaßt zu haben, auch durchhalten. Dann müssen Sie die ganze Wucht der Last tragen, das ist alles sehr einfach: Der ganze Ernst des Bonner Lebens kommt jetzt auf alle Beteiligten zu." 135

Drei Tage später - unmittelbar nach dem Frühstück mit Heck - hielt Wehner während der Haushaltsdebatte im Bundestag eine, wie Kiesinger sie kennzeichnete, "hysterische“ Rede. Der CDU/CSU rief er zu: „Sie können mit uns nicht umgehen wie mit Schulbuben." Mit der Sozialdemokratie könne die Union kein Spiel treiben, wie sie es bisher mit ihren Koalitionspartnern getan habe. Den politischen Konkurs, den sie verschuldet habe,

132 Vgl. Heck, Der Europäer als Landesvater.

${ }^{133} \mathrm{Vgl}$. Heck, Gespräch mit dem Verfasser, 4.10.1988.

${ }^{134}$ BPA, Heck in der ARD am 20.11.1966, Anhang III, S. 2.

${ }^{135}$ BPA, Wehner in der ARD am 20.11.1966, Anhang I, S. 2. 
müsse sie selbst verantworten. Daß die Union sich so verhalten habe, wie sie sich auch jetzt wieder zu verhalten suche, sei genau jene Einstellung, an der das bundesdeutsche Volk und der bundesdeutsche Staat litten ${ }^{136}$.

Die Rede löste Verwirrung aus. Niemand aus der SPD kannte den Anlaß. Die Abgeordneten der Fraktion reagierten verstört. Was denn die Rede habe bedeuten sollen, fragte Hans Apel den amtierenden Fraktionsführer in einer Sondersitzung. In der Fraktion sei man über die Möglichkeit beunruhigt, daß sie in ihrer Entscheidung nicht mehr frei sei. Der Berliner Abgeordnete Klaus Dieter Arndt kritisierte, die Rede habe sich angehört, als ob die Sozialdemokraten keine Regierungsbeteiligung anstrebten ${ }^{137}$. Wehner aber gelang es durch die Fürsprache anderer Redner, vor allem Schmidts und Gustav Heinemanns, die Fraktion zu einer einmütigen Billigung seiner Rede zu veranlassen. Von Hecks Bedingung am Frühstückstisch, ohne ein Bündnis auf Landesebene in Düsseldorf werde es keine Große Koalition in Bonn geben, erfuhr die Fraktion allerdings kein Wort. Inzwischen hatte sich auch das Gemüt Wehners wieder beruhigt. Nach der Rede am Vormittag hatte Kiesinger mit Wehner telefoniert. Der Christdemokrat wollte wissen, was es mit der Rede auf sich habe. Doch Wehner ließ sich auf keine Diskussion ein. „Es ist aus, es ist aus!" rief er. Die Absprachen seien hinfällig, wenn die Forderung Hecks nach einer Großen Koalition in Düsseldorf weiter bestehenbliebe. Wehner schien einem Nervenzusammenbruch nahe. „Was haben Sie denn mit dem Wehner gemacht?“, kritisierte Kiesinger Heck anschließend, „Der Mann ist ja mit seinen Nerven am Ende. "138 Der Kanzlerkandidat entschuldigte sich bei Wehner, er habe nichts von Hecks eigenmächtiger Vorgehensweise gewußt. Die alten Zusagen seien weiterhin gültig, egal, ob in NordrheinWestfalen eine sozialliberale Koalition gebildet werde oder nicht.

Damit war das Thema erledigt. Am späten Abend traten die beiden Parteiführer gemeinsam vor die Kameras. Kiesinger, der sich bis dahin in der Öffentlichkeit mit eindeutigen Aussagen zurückgehalten hatte, stellte eine für die Journalisten überraschend optimistische Prognose: Er habe die Hoffnung, daß vielleicht noch im Lauf der Woche ein endgültiges Ergebnis erzielt werden könne. Diese Zuversicht habe sich bei ihm an diesem Tag gefestigt $t^{139}$. Sehr viel nüchterner wirkte Wehner, der erstaunlich offen erklärte: „Für uns handelte es sich [...] darum, [...] zu verhüten, daß der Versuch, auf einer sauberen Grundlage über die neu zu bildende Regierung zu sprechen und schließlich auch zu verhandeln - vom Verhandeln sind wir ja noch weit entfernt -, daß dieser Versuch nicht wieder schon in den Anfängen verwischt wird. “140 Vor dem Hintergrund der Auseinandersetzung um den Haushalt am Vormittag im Parlament mußte das so klingen, als ob es der Sozialdemokratie gelungen sei, den angeblichen Versuch der CDU/CSU zu verhindern, ihre Verantwortlichkeit für die katastrophale Haushaltslage zu leugnen. An Kiesinger und Heck enthielt die Äußerung eine Warnung, das gemeinsame Bündnis werde nicht nach Sonderbedingungen der Union zu haben sein. Falls CDU/CSU dennoch Bedingungen stellten, werde nämlich aus der Koalition nichts werden.

\footnotetext{
${ }_{136}$ VdDB, 5. Wahlperiode, 73. Sitzung, 23.11.1966, S. $3442 \mathrm{ff}$.

${ }_{137} \mathrm{Vgl}$. AdsD, Protokolle, Fraktionssitzung vom 24.11.1966, S. 3.

${ }^{138}$ Heck, Gespräch mit dem Verfasser, 4.10.1988, und Kiesinger, Gespräch mit Baring, 16.6.1977.

${ }^{139} \mathrm{Vgl}$. BPA, Kiesinger im ZDF am 23.11.1966, Anhang I, S. 1.

${ }^{140} \mathrm{BPA}$, Wehner im ZDF am 23.11.1966.
} 


\section{Brandt statt Gerstenmaier als Außenminister}

Kaum hatte Wehner diesen Versuch, die Absprachen einseitig zu ändern, abgewehrt, war er es, der seinerseits die Bedingungen für das Bündnis einseitig zugunsten der SPD abwandelte. Als alles schon besprochen war, erklärte Wehner Kiesinger am 27. November 1966 kleinlaut, der Vorsitzende Brandt bestehe nun doch darauf, Außenminister einer Großen Koalition zu werden. Das schien sie noch einmal zu gefährden. Der SPD-Fraktionsführer persönlich hatte in den Vorgesprächen behauptet, Brandt werde nur ein kleines Ressort übernehmen, um sich besser der Parteiarbeit widmen zu können. Gedacht war an das Bundesministerium für wissenschaftliche Forschung, was der Regierende Bürgermeister von Berlin im persönlichen Gespräch mit Kiesinger zunächst bestätigte ${ }^{141}$. Als aber andere SPD-Vorstandsmitglieder - insbesondere Schmidt ${ }^{142}$ - darauf drangen, der Parteivorsitzende müsse das Amt des Außenministers übernehmen, ließ sich Brandt überzeugen. Wehner überbrachte allerdings die neue Forderung zu einem Zeitpunkt, als Kiesinger sich längst anderweitig gebunden hatte. Mit seinem Landsmann Gerstenmaier hatte er, wie schon erwähnt, vor der Wahl in der Fraktion ausgemacht, daß der gewählte Kanzlerkandidat den Unterlegenen zum Außenminister berufen würde. Gleich nach dem Gespräch mit Brandt vom 25. November 1966 telefonierte Kiesinger daher mit dem Bundestagspräsidenten. Man habe sich mit Brandt auf das Wissenschaftsressort geeinigt. Ob er, Gerstenmaier, jetzt Außenminister werden wolle? Gerstenmaier zögerte nicht, nahm an, bat allerdings um ein offizielles Angebot. Kiesinger schickte es noch am selben Tag, und die Antwort kam umgehend. Sein Brief enthielt sogar erste Anregungen für eine Umgestaltung der Ressorts. Er wolle das für die FDP eingerichtete Entwicklungshilfeministerium wieder auflösen, schrieb Gerstenmaier ${ }^{143}$.

Auch außenpolitische Richtlinien übersandte er in der Anlage „zur vertraulichen Kenntnis“. Gerstenmaier visierte zwei Ziele an: einmal die Überwindung der Gegensätze in der Unionsfraktion, also des Gegensatzes zwischen „Atlantikern“ und „Gaullisten“. Zum anderen unterstützte er moderate Zugeständnisse in der Ostpolitik, die „eine allgemeine Übereinstimmung auch mit dem Koalitionspartner herbeiführen“ könnten. Er sei bereit, in der Deutschlandpolitik, und das heiße auch „im Verhalten zu Ost-Berlin, genau erwogene neue Schritte zu tun“, und außerdem, „mit dem Kreml zu neuen Gesprächen und Verhaltensweisen zu kommen" 144 .

In erster Linie wollte Gerstenmaier harmonische Beziehungen zu Frankreich wiederherstellen. Zum Thema „Konzeption eines geeinten Europas“ hieß es in dem Text, man könne an de Gaulles Europa der Vaterländer nicht vorbeigehen. Aber Robert Schumans Entwurf des geeinten Europa sei die bessere Konstruktion. Gerstenmaier gab also der supranationalen Lösung eines geeinten Europas den Vorzug vor de Gaulles Europa der Nationalstaaten ${ }^{145}$. Zu weiteren, detaillierten Vorschlägen Gerstenmaiers kam es dann nicht mehr. Nur zwei Tage nach seiner schriftlichen Zusage rief ihn Kiesinger am Sonn-

${ }^{141}$ Vgl. Knorr, Entscheidungsprozeß, S. 89. Das Gespräch fand am 25.11.1966 statt; siehe auch Witter, Prominentenportraits, S. 18; dort findet sich Brandts Erläuterung auf einem Spaziergang im September 1968.

142 Vgl. Witter, S. 18: „Wenn du schon Vormann der SPD bist, mußt du auch die zweitwichtigste Aufgabe im Kabinett übernehmen."

${ }^{143}$ Vgl. AdKASt, Kiesinger I - 226, D/IV.6, A 003, Gerstenmaier an Kiesinger vom 25.11.1966.

${ }^{14}$ Gerstenmaier, Streit und Friede, S. 541.

${ }^{145}$ Ebenda, S. 534. 
tag, den 27. November an und erklärte bedrückt die neue Lage. Wehner sei bei ihm gewesen und habe dargelegt, daß die SPD nunmehr doch das Außenministerium und das Amt des Vizekanzlers für ihren Vorsitzenden fordere. Ob die Partei diese Frage zur Koalitionsfrage erklärt habe, fragte Gerstenmaier überrascht. Kiesinger bejahte. Gerstenmaier gab nach: Wenn es anders nicht gehe, entlasse er ihn aus seinem Wort.

Damit hatte die SPD ihren zweiten wichtigen Erfolg bei der Regierungsbildung erzielt. Gerstenmaier hat später enttäuscht sein Nachgeben damit gerechtfertigt, daß Kiesinger damals, im November 1966, nicht auf Kampf gestimmt gewesen sei. Vielleicht hat Gerstenmaier mit dieser Behauptung recht. Wenn sich Kiesinger für seinen Außenministerkandidaten eingesetzt, also beispielsweise ein Ultimatum gestellt hätte, dann hätte die SPD möglicherweise nachgegeben. Andererseits hätte ein Scheitern der Koalitionsverhandlungen auch das Ende seiner Kanzlerkandidatur bedeutet. Diesen Preis empfand Kiesinger als zu hoch.

\section{Das Kabinett: Abgrenzung der Ministerien}

Mit der Übernahme des Außenministeriums durch Brandt gerieten die Pläne in Unordnung, wer von beiden Parteien wie viele Minister stellen sollte. Ursprünglich hatte Kiesinger vorgehabt, seinem Koalitionspartner eine Parität der Ministerposten anzubieten: Beide Seiten sollten die gleiche Anzahl von Ministern stellen, aber die Christdemokraten im Besitz der wichtigeren Ämter sein. Das Auswärtige Amt sollte von Gerstenmaier geleitet werden, das Wirtschaftsministerium von Strauß. „Ich wollte Strauß als Wirtschaftsminister“, sagte Kiesinger später, „aus der Erwägung: Wenn wir die Rezession überwinden, wird das dem Wirtschaftsminister zugeschrieben werden. “ ${ }^{146}$ Schmidt hätte Verteidigungs- oder Finanzminister werden können, aber man sei um den versierten Experten, den früheren Wirtschaftssenator in Berlin, Schiller, als Wirtschaftsminister nicht herumgekommen. Und Strauß sei zudem mit „heraushängender Zunge“ dem Amt des Finanzministers hinterhergelaufen. Darüber hinaus wollte der Kanzlerkandidat den Regierenden Bürgermeister Berlins für das Ministerium für gesamtdeutsche Fragen gewinnen ${ }^{147}$.

Doch dann kam alles anders: Brandt verlangte das Außenministerium, und damit geriet die Arithmetik durcheinander. In einer langen Nachtsitzung am 29. November wurde eine Einigung erzielt. Die Sozialdemokraten erhielten das Außenministerium und das Wirtschaftsministerium, dafür verzichteten sie insgesamt auf ein Ministerium. Die CDU/CSU stellten insgesamt zehn, die SPD noch neun Amtschefs. Offen blieb die Frage, ob Umgliederungen von Referaten oder anderen Einrichtungen von einem ins andere Ministerium möglich sein würden oder nicht. Dieses Problem war vor allem durch den neuen Verteidigungsminister aufgeworfen worden. Schröder hatte seit Beginn der Verhandlungen Bedingungen gestellt. Zunächst ließ er keinen Zweifel daran, daß nur das Außenministerium für ihn in Frage komme ${ }^{148}$. Als er dieses Ziel nicht erreichen konnte, suchte er das ihm angebotene Verteidigungsministerium aufzuwerten. Wie eine Zeitung meldete, sollte dem früheren Außenminister für den Wechsel auf die Bonner Hardthöhe auch noch die Kontrolle über den Bundesnachrichtendienst übertragen und der Bun-

\footnotetext{
146 Kiesinger, Gespräch mit Baring, 16.6.1977.

${ }^{1+7}$ Vgl. Der Spiegel, 5.12.1966, S. 34. „Dafür sind Sie doch durch Ihr Berliner Amt prädestiniert“, soll er Brandt gesagt haben.

${ }^{148}$ Vgl. Rheinische Post, 25.11.1966.
} 
desverteidigungsrat in sein Ministerium eingegliedert werden ${ }^{149}$. Der Verteidigungsrat war deswegen eine wichtige, einflußreiche Institution, weil er die Außen-, Sicherheitsund Innenpolitik koordinierte. Die Diskussionen um den Atomsperrvertrag beispielsweise fanden in den Jahren der Großen Koalition in diesem Gremium statt. Aber es gab noch andere Gerüchte: Der Spiegel berichtete, daß Schröder das Nato-Referat aus dem Außenministerium in das der Verteidigung eingliedern wolle ${ }^{150}$.

Kiesinger hatte allerdings kein Interesse daran, die Machtposition seines künftigen Verteidigungsministers zu stärken. Es ging ihm im Gegenteil darum, Schröder in die Kabinettsdisziplin einzubinden. Das persönliche Verhältnis hatte sich noch verschlechtert, als Kiesinger von Heck erfuhr, daß Schröder - ein ehemaliges SA-Mitglied - nicht davor zurückgeschreckt war, nach Kiesingers Wahl auf dessen Vergangenheit als Parteigenossen hinzuweisen. Das Klima blieb daher zwischen beiden Rivalen frostig. Als Schröder davon Wind bekam, daß einer seiner profiliertesten Gegner, der CSU-Politiker Guttenberg, als Staatsminister für das Kanzleramt vorgesehen war, bemerkte der Verteidigungsminister gegenüber dem künftigen Regierungschef empört, das sei ja wohl ein Himmelfahrtskommando. Darauf soll Kiesinger kühl geantwortet haben: „Das fragt sich nur, für wen! “ 151

Vor diesem Hintergrund ließ Kiesinger das Ministerium für die Angelegenheiten des Bundesverteidigungsrates auflösen. Aber anstatt den Rat wie gefordert auf die Hardthöhe zu verlagern, gliederte der Regierungschef ihn in das Bundeskanzleramt ein. Die beiden Koalitionsparteien kamen schließlich überein, daß ein Austausch oder eine Umgliederung bestimmter Referate nur innerhalb jener Ministerien zulässig sei, die von Parteikollegen geführt würden. Dadurch war auch die Erfüllung von Schröders zweiter Forderung ausgeschlossen; das Nato-Referat verblieb im Außenministerium.

Mehr Erfolg erzielte dagegen Schröders Vorschlag, den früheren Verteidigungsminister Kai-Uwe von Hassel - einen "Atlantiker" - in die Regierung aufzunehmen. Wie bei der Besetzung der Verhandlungskommission spielte die konfessionelle Zugehörigkeit auch bei der Verteilung der Ministerposten eine wichtige Rolle. Die Tatsache, daß die katholischen Mitglieder Heck, Hermann Höcherl, Hans Katzer, Lücke, Strauß durch die Hinzunahme des früheren Wirtschaftsministers Kurt Schmücker mit sechs Ministern die Mehrheit bildeten, sprach für eine Berufung des Protestanten von Hassel. Schmücker hatte versucht, für sich ein sogenanntes Europaministerium zu fordern. Dazu schrieb Schröder Kiesinger unter dem 29. November zum Stichwort „v. Hassel“: „Ich weiß nicht, ob Sie auf die Vorschläge von Schmücker eingehen wollen oder können. Eine Zustimmung der SPD dazu halte ich für unwahrscheinlich. Sollte es aber zu der Bildung eines solchen Ministeriums kommen, wäre die Einbeziehung von Entwicklungshilfe nicht nötig oder gar zwingend. Ich möchte mich sehr dafür aussprechen, von Hassel mit Blick auf die evangelische Seite im Kabinett zu behalten. Das E-Ministerium wäre für ihn (und er dafür) besonders geeignet." 152

Der neue Verteidigungsminister behielt recht mit der Annahme, daß die SPD einem Europaministerium nicht zustimmen werde, und für den Bereich Entwicklungshilfe übernahm die SPD selbst die Verantwortung. Das Amt wurde mit dem Abgeordneten HansJürgen Wischnewski besetzt. Am Ende zog Schmücker in das Schatzministerium ein,

\footnotetext{
149 Vgl. Frankfurter Rundschau, 30.11.1966.

150 Vgl. Der Spiegel, 5.12.1966, S. 33.

${ }^{151}$ Ebenda, S. 34; siehe auch Heck, Gespräch mit dem Verfasser, 4.10.1988.

152 AdKASt, Kiesinger I - 226, D/IV.6, A 007, Schröder an Kiesinger vom 29.11.1966.
} 
von Hassel wurde Vertriebenenminister. Damit schien alles für die Vereidigung des neuen Kabinetts am 1. Dezember 1966 im Bundestag geklärt zu sein. Bundestagspräsident Gerstenmaier forderte die Ministeraspiranten auf, schriftlich zu erklären, ob sie ihre Eidesformel „religiös“ oder "freigeistig“ wünschten. Doch alle Minister wählten die christliche Formel.

Auf dem traditionellen Regierungsphoto auf der Treppe vor der Villa Hammerschmidt, dem Sitz des Bundespräsidenten, standen die wichtigsten Personen ganz hinten. In der obersten Reihe links blickte ein scheinbar in sich versunkener Strauß, der neue Finanzminister, zwischen den Köpfen von Schiller und von Hassel hindurch auf Bundeskanzler und Vizekanzler, die vorne links, voneinander abgewendet, neben Bundespräsident Lübke posierten. Auf der anderen Seite war Wehner, der sich, aufgeräumt und heiter wirkend, mit dem neuen Familienminister Heck unterhielt. Die Krise, die Heck noch wenige Tage zuvor ausgelöst hatte, schien völlig vergessen. Schröder stellte sich ganz nach links in die zweite Reihe; anders als drei Jahre zuvor - damals konnte man ihn noch in der Mitte neben Bundespräsident Lübke sehen - stand er jetzt im Abseits. Die scherzhafte Unterhaltung, die er mit Arbeitsminister Katzer zu führen schien, konnte nicht darüber hinwegtäuschen, daß der Verteidigungsminister nicht so recht in das Gesamtbild der neuen Regierung paßte ${ }^{153}$.

${ }^{153}$ Vgl. Der Spiegel, 5.12.1966, S. 29, und Hildebrand, Erhard, S. 262, hier allerdings weniger deutlich. 